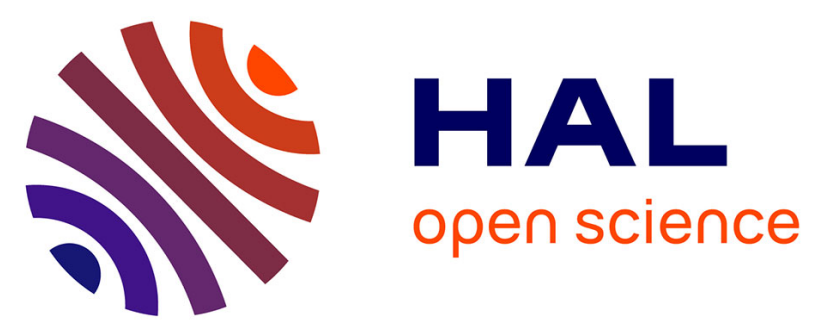

\title{
Longitudinal Responses of the Equatorial/Low-Latitude Ionosphere Over the Oceanic Regions to Geomagnetic Storms of May and September 2017
}

\author{
A. O. Akala, E. O. Oyeyemi, P. O. Amaechi, S. M. Radicella, B. Nava, \\ Christine Amory-Mazaudier
}

\section{To cite this version:}

A. O. Akala, E. O. Oyeyemi, P. O. Amaechi, S. M. Radicella, B. Nava, et al.. Longitudinal Responses of the Equatorial/Low-Latitude Ionosphere Over the Oceanic Regions to Geomagnetic Storms of May and September 2017. Journal of Geophysical Research Space Physics, 2020, 125 (8), 10.1029/2020JA027963 . hal-02926010

\section{HAL Id: hal-02926010 https://hal.science/hal-02926010}

Submitted on 31 Aug 2020

HAL is a multi-disciplinary open access archive for the deposit and dissemination of scientific research documents, whether they are published or not. The documents may come from teaching and research institutions in France or abroad, or from public or private research centers.
L'archive ouverte pluridisciplinaire HAL, est destinée au dépôt et à la diffusion de documents scientifiques de niveau recherche, publiés ou non, émanant des établissements d'enseignement et de recherche français ou étrangers, des laboratoires publics ou privés. 
Akala Andrew Oke-Ovie (Orcid ID: 0000-0002-9754-9360)

\title{
Longitudinal responses of the equatorial/low latitude ionosphere over the oceanic regions to
} geomagnetic storms of May and September, 2017

\author{
A. O. Akala ${ }^{1,2,3,5}$, E. O. Oyeyemi ${ }^{1}$, P. O. Amaechi ${ }^{1,4}$, S. M. Radicella ${ }^{5}$, B. Nava ${ }^{5}$,
}

\section{Amory-Mazaudier ${ }^{5,6}$}

${ }^{1}$ Department of Physics, University of Lagos, Akoka, Yaba, Lagos, Nigeria

${ }^{2}$ Distance Learning Institute, University of Lagos, Akoka, Yaba, Lagos, Nigeria

${ }^{3}$ Maritime Institute, University of Lagos, Akoka, Yaba, Lagos, Nigeria

${ }^{4}$ Department of Physical Sciences, Chrisland University, Abeokuta, Nigeria

${ }^{5}$ The Abdus Salam International Centre for Theoretical Physics, Trieste, Italy

${ }^{6}$ LPP, CNRS/Ecole Polytechnique/Sorbonne Université/Université Paris-Sud/Observatoire de Paris, 4 Place Jussieu, 75252 Paris, France

\section{Abstract}

This study presents the longitudinal dependence of responses of the equatorial/low latitude ionosphere over the oceanic regions to geomagnetic storms of 28th May and 8th September, 2017. We investigated the interplanetary origins of the storms. Total Electron Content (TEC) data were obtained from Global Navigation Satellite System stations, located around the oceanic areas in the equatorial/low latitude regions. The Rate of change of TEC Index (ROTI) was used as a proxy for ionospheric irregularities over the study locations. Further, variations of the horizontal component of the Earth's magnetic fields, obtained from ground-based magnetometers were studied. We used ionospheric disturbance currents, polar cap and auroral electrojet indices to monitor the storm-time electric fields. The May, 2017 storm was driven by sheath and magnetic cloud fields, while the September, 2017 storm was driven by sheath fields. We observed a comparative dominance of TEC intensities over the Oceans than over the landlocked areas. Empirically, our results validated a theoretical suggestion of the existence of a dynamic ocean-ionosphere coupling made by Godin et al. [2015]. Prompt Penetration Electric Fields (PPEF) was observed to be a key factor that controls TEC responses to storms. PPEFs caused TEC enhancements, mainly over the Pacific Ocean longitudes during the May, 2017 storm and enhanced TEC over the Atlantic Ocean and the Pacific Oceans longitudes during the September, 2017 storm. These PPEFs triggered irregularities over the Pacific

This article has been accepted for publication and undergone full peer review but has not been through the copyediting, typesetting, pagination and proofreading process which may lead to differences between this version and the Version of Record. Please cite this article as doi: 10.1029/2020JA027963 
Ocean longitudes, particularly during the main phase of May, 2017 storm. Irregularities were generally inhibited by the September, 2017 storm.

Key words: Geomagnetic storms, ionospheric irregularities, total electron content, storm-time electric fields

\section{Introduction}

The occurrences of geomagnetic storms cause harmful disturbances in the geo-space environment [Chapman and Ferraro, 1931]. Geomagnetic storms are caused by solar features, such as; (i) the coronal mass ejections (CMEs) and, (ii) high speed streams (HSS) from the Sun's coronal holes [Burlaga and Lepping, 1977, Gonzalez et al., 1994, Gopalswamy et al., 2009, Tsurutani et al., 2011]. CME has two geo-effective components; sheath fields [Guo et al., 2011] and magnetic cloud fields [Burlaga et al., 1981, Lepping et al., 2015]. Another driver of geomagnetic storms is the Co-rotating Interaction Region (CIR) and they (CIRs) are manifestations of HSS [Gosling, 1993, Gosling and Pizzo, 1999].

Geomagnetic storms occurrences can significantly modify the ionosphere with resultant overbearing negative effects on space- and ground-based systems [NRC, 2008, Akala et al., 2013a, b]. One of the ionospheric parameters which are easily modified by the occurrences of geomagnetic storms is the Total Electron Content (TEC). TEC is the number of electrons in a column of $1 \mathrm{~m}^{2}$ cross-sectional area between the Global Navigation Satellite System (GNSS) satellite and the receiver [HofmannWellenhof et al., 1994]. Variations in TEC can cause range errors for navigation signals in the order of 1 TECU to $0.163 \mathrm{~m}$ range error at GNSS L1 frequency (1.5754 GHz)[Klobuchar, 1996, Akala et al., 2013a, b]. It has been reported that sharp and rapid variations in TEC are sine qua non to occurrences of ionospheric plasma-density irregularities [Valladares et al., 1996, Akala et al., 2011]. Ionospheric irregularities cause scintillations of radio waves [Kintner et al., 2007], and severe scintillations on the other hand can cause loss of signal and cycle slips to trans-ionospheric radio systems [Akala et al., 2012, 2014, 2015, 2016, 2017].

During geomagnetic storms, equatorial/low latitude ionosphere is usually affected through the effect of PPEF [Vasyliunas 1970, 1972] and Disturbance Dynamo Electric Field (DDEF) [Blanc and Richmond, 1980]. PPEFs are eastward during the day, and westward at night [Senior and Blanc, 1984]. Its magnetic signature, known as Disturbance Polar number 2 (DP2) [Nishida, 1968] is caused by electric current systems related to magnetospheric convection electric field [Nava et al., 2016, Amory-Mazaudier et al., 2017]. Depending on its configuration, either eastward or westward, PPEF can affect $E \times B$ drift, resulting in significant increase or decrease in TEC, as well as affecting the lifting of the post sunset F-layer to higher altitudes. Thus, the generation of irregularities through the 
Rayleigh Taylor Instability (RTI) $[A b d u, 2012]$ is affected by the presence of PPEF. DDEF results from the dynamo action of storm time winds generated by Joule heating [Blanc and Richmond, 1980] and manifests as a negative excursion in the daily horizontal component of the Earth's magnetic field. Its magnetic signature is referred to as the ionospheric disturbance dynamo (Ddyn) [Le Huy and Amory-Mazaudier, 2005].

Fejer et al. [2008] reported the seasonal and longitudinal dependence of equatorial disturbance vertical plasma drifts and concluded that opposite effects do exist between the magnitudes of PPEF and DDEF drifts across longitudes. As Fejer and Scherlies [1997] pointed out, prompt penetration drifts are mostly upward during the day and downward at night. The evening downward drifts have largest values in the eastern hemisphere, while the nighttime upward drifts maximize in the far Asia zone [Fejer et al., 2008, Fejer, 2011]. Another longitudinal study by Kuai et al. [2016] revealed a difference in the ionospheric response in the Asian-Australian and the American sectors due to the effects of PPEF and DDEF during the storm of March, 2015. In a similar effort, Patra et al. [2016] linked the occurrence of strong irregularities during the storm of March, 2015 to an eastward PPEF which caused a strong uplift of the F-layer over the Indian longitude, while Amaechi et al. [2018a, b] attributed the inhibited ionospheric irregularities over the African longitude to DDEF effects during the storm of March, 2015. These observations imply that PPEF and DDEF exhibit remarkable local time dependence which plays an important role in the longitudinal difference in the responses of the low latitude ionosphere to geomagnetic storms [Kuai et al., 2016].

From the standpoint of ground-based measurements, one cardinal hindrance to our global understanding of the storm-time electrodynamics of the equatorial/low latitude ionosphere is the paucity of ionospheric studies over the oceanic regions, which is largely due to the challenges of installing ionospheric sensors on the surface of the oceans. Paradoxically, oceans cover about seventy percent of the Earth's surface. Although, over the past decades, satellite data have been quantitatively used to resolved the above concern [Burke et al., 2004, Gentile et al., 2006, 2011, Hei et al., 2005, Kil et al., 2009a, b, Huang et al., 2014, Huang and Hairston, 2015, Carter et al., 2016, Akala et al., 2017, Astafyeva et al., 2018]. However, satellites measurements could have inherent challenges, such as data adulteration by propagating medium interference, satellite altitude variations, instruments' calibration error due to age, data archival and retrieval errors, amongst others. For data integrity control, validation of satellite data with corresponding ground-based data remains sacrosanct.

Akala et al. [2019] using ground-based GNSS receivers data, reported that coastal environments are more prone to ionospheric irregularities than landlocked areas. In a similar vein, Saito [2013] reported that GNSS stations surrounded by large bodies of water are vulnerable to multipath effects due to the fact that water bodies and ice act as good reflectors of GNSS signals. Additionally, heat absorption and circulations are predominant over the ocean surface than over the land [Forbes et al., 2007]. 
Consequently, the uneven heating of the atmosphere over the ocean leads to increase in atmospheric convections which create non-migrating tides that influence neutral wind circulations in the upper atmosphere [Fuller-Rowell et al., 1994], and invariably, influence the electrodynamics of the ionosphere [Hagan et al., 2001, Lau and Yang, 2015]. Furthermore, previous studies on tsunamis have also provided evidences of the existence of connections between ocean surface gravity waves and acoustic gravity waves in the ionosphere [e.g., Hickey et al., 2009, 2010, Makela et al., 2011, Komjathy et al., 2012, Occhipinti et al., 2013]. However, these studies only investigated ionospheric gravity waves after tsunamis had occurred, consequently, prediction of tsunamis prior to their occurrences, from the perspective of ionospheric dynamics remains an unresolved issue. Accordingly, detailed understanding of the physical processing involved in the ocean-ionosphere coupling is required for necessary parameterization and development of instrumentation for simultaneous monitoring of ocean surface gravity waves and ionospheric acoustic gravity waves on a global scale. From a theoretical perspective, Godin et al. [2015] connected surface gravity waves in the oceans with ionospheric acoustic gravity waves and their study was experimentally validated by Zabotin et al. [2016]. However, Zabotin's et al. [2016] data analysis only covered a specific region in the North Atlantic. These authors recommended global validation of their results. To this end, this study investigates the longitudinal variations of storm-time electric field, characterized alongside with TEC and ionospheric irregularities over the global oceanic regions during 28th May and 8th September, 2017 storms.

\section{Data and method of analysis}

Two intense (-200 nT $\leq$ Dst $\leq-100 \mathrm{nT})$ geomagnetic storms that occurred on the 28th of May, 2017 and 8th of September, 2017, respectively were studied. Interplanetary Magnetic Field (IMF) and solar wind plasma data were measured by the Advanced Composition Explorer (ACE) satellite. ACE data were obtained at https//omniweb.gsfc.nasa.gov/hw/hmtl. ACE satellite is located close to the $\mathrm{L}_{1}$ Lagrangian point (a distance of about $240 \mathrm{R}_{\mathrm{E}}$ from the Earth). This large distance causes propagation delay in the travel time of solar wind plasma and the embedded IMF from the satellite to the Earth's magnetosphere. For this reason, we normalized the data by a time shift of 52 minutes [Chakrabarty et al., 2005, Yizengaw et al., 2011, Amaechi et al., 2018b]. ICME transients consist of the sheath and magnetic cloud fields. Sheath fields are usually behind a shock at the point when Bz turns southward with simultaneous sharp increase in all IMF and solar wind parameters (forward shock) or decrease in all these parameters, except increase in solar wind speed (reverse shock). Sheath fields are sandwiched in-between shocks and the leading edges of ICMEs. Magnetic cloud fields are associated with low solar wind temperature and solar wind density, preceded by shocks and sheath fields [Burlaga et al., 1981]. In addition to the southward turning of Bz, CIRs are diagnosed by sharp increase in the IMF and solar wind parameters, except solar wind speed and solar wind temperature 
which are often delayed before gaining momentum to increase at later times [Gosling, 1993, Gosling and Pizzo, 1999].

The Auroral Electrojet (AE), Polar Cap North (PCN) and Polar Cap South (PCS) indices were obtained from the World Data Center (WDC) for Geomagnetism, Kyoto (htpp://wdc.kugi.kyotou.ac.jp). We used ground-based magnetometers' data within the equatorial/low latitude strip around the oceanic regions to monitor changes in ionospheric currents during the storms. The magnetometers are owned by the Institut de Physique du Globe de Paris (IPGP) and data are made available via INTERMAGNET. The geographic locations of the GNSS and magnetometer stations are shown in Figure 1. SYM-H index data were used to compute ionospheric electric current disturbance (Diono). SYM-H and ASYMH data were obtained from isgi.unistra.fr. SYM-H profile changes rapidly the Earth's magnetic field $(\mathrm{H})$ and this also manifested clearly on the PC and AE profiles.

The horizontal component of the Earth's magnetic field $(\mathrm{H})$ was computed from the north component (X) and the south component $(\mathrm{Y})$ of the field as $\mathrm{H}=\sqrt{\mathrm{X}^{2}+\mathrm{Y}^{2}}$. The mean quiet horizontal component field was then estimated during five magnetic quiet days using equation (1).

$$
\overline{\Delta \mathrm{H}}=\frac{1}{\mathrm{n}} \sum_{\mathrm{i}=1}^{\mathrm{n}}\left(\mathrm{H}_{\text {quiet }}\right)_{\mathrm{i}}
$$

where $\mathrm{n}=5$ is the number of magnetic quiet days in a month.

We used the International Quiet Days (IQDs), selected from the German Research Centre for Geosciences website (ftp://ftp.gfz-potsdam.de) as the magnetic quiet days. The day-by-day variability was accounted for by taking the standard deviation of $\mathrm{H}_{\text {quiet }}$ during the magnetic quiet days. The ionospheric electric current disturbance (Diono) which is the magnetic effect of the disturbed ionospheric electric field current systems were estimated [Shimeis et al., 2012, Fathy et al., 2014, Azzouzi et al., 2015, Nava et al., 2016, Amory-Mazaudier et al., 2017].

$$
\text { Diono }=\Delta \mathrm{H}-\mathrm{SYMH} \cdot \operatorname{Cos} \lambda-\mathrm{Sq}
$$

where $\Delta \mathrm{H}$ in equation (2) is the observed component of the magnetic field, SYMH is an estimation of the ring current, $\lambda$ is the geomagnetic latitude and $\overline{\Delta H}$ is the mean monthly quiet $\Delta \mathrm{H}$ component of the Earth's magnetic field. To first approximation, over the middle and low latitudes, Diono is the sum of DP2 and Ddyn [Le Huy and Amory-Mazaudier, 2005].

$$
\text { Diono }=\text { DP2 }+ \text { Ddyn }
$$

where DP2 in equation (3) is the disturbance polar number 2 current and Ddyn is the disturbance dynamo current. At the equator, there is a disturbance of the ionospheric current Diono, only on the dayside when there are ionospheric conductivities in the dynamo layer. DP2 is the magnetic disturbance related to PPEF [Nishida, 1968], while Ddyn is magnetic disturbance related to DDEF [Blanc and Richmond, 1980]. We used band-pass filter with bandwidth of 18-28 hours to extract 
Ddyn from Diono, while high-pass filter with a maximum pass period of about 4 hours was used to extract DP2 from Diono.

We extracted Slant TEC (STEC) from GNSS observables data that were obtained from the University NAVSTAR Consortium (UNAVCO) website (htpp://www.unavco.org/data/data.html). The data were in Receiver Independent Exchange (RINEX) format and they were processed by Gopi TEC processing software [Seemala, 2010]. The carrier phase was leveled with pseudorange measurements. This further entailed detecting and correcting cycle slips [Blewitt, 1990] and calibrating STEC using satellite and estimated receiver biases [Ciraolo et al., 2007]. The calibrated STEC was converted to VTEC using mapping function at ionospheric pierce point of $350 \mathrm{~km}$ [Ma and Maruyama, 2003, Mannucci et al., 1993]. Multipath effects were eliminated by adopting an elevation cut-off of $30^{\circ}$. VTEC is hereafter referred to as TEC. Ground-based TEC measurements were validated with SWARM A TEC measurements at ftp://swarm-diss.eo.esa.int/. SWARM is European Space Agency's constellation mission for Earth observation. The mission consists of three identical satellites (A, B, and C). SWARM A and C form the lower pair of satellites flying side-by-side (1.4 ${ }^{\circ}$ longitudinal separation) at $470 \mathrm{~km}$ altitude, while SWARM B flies at $520 \mathrm{~km}$ altitude.

We use rate of change of TEC index (ROTI) as proxy for ionospheric irregularities [Pi et al., 1997, Oladipo and Schüler, 2013, Amaechi et al., 2018b, Zaourar et al., 2017, Yizengaw et al., 2018].

$$
\text { ROTI }=\sqrt{<R O T^{2}>-<R O T>^{2}}
$$

where ROT in equation (4) is the rate of change of TEC in TECU per minute.

An irregularities threshold of $0.5 \mathrm{TECU} / \mathrm{min}$ was set for all visible satellite at cut off elevation of $30^{\circ}$.

Finally, we used JASON-2 satellite sea level anomaly data (ftp://ftpcoastwatch.noaa.gov/pub/socd//sa/johnk/coastwatch/j2) and optimum interpolation sea surface temperature data (https://www.ncdc.noaa.gov/oisst) to characterize the global ocean environments during the time intervals of the occurrences of the two storms. JASON-2 sea level anomaly data were not available during the 28th May storm. JASON-2 is a joint U.S./European Ocean Surface Tomography Mission flying at 1,336 km altitude.

\section{Results}

\subsection{8th May, 2017 GS event}

Figure 2(a-e) shows variations of solar wind speed, $V_{x}(\mathrm{~km} / \mathrm{s})$, IMF Bz $(\mathrm{nT})$, PCN and PCS indices $(\mathrm{mV} / \mathrm{m})$, SYM-H (nT) and AE index (nT) from 23rd May-2nd June, 2017. The dash-lines on the figure represent forward shock. At about 1536 UT on the 27th of May, there was a forward shock that marked the arrival of a CME. $\mathrm{V}_{\mathrm{x}}$ increased sharply to $367 \mathrm{~m} / \mathrm{s}$, while SYM-H gradually decreased, reaching a minimum value of $-145 \mathrm{nT}$ at $0800 \mathrm{UT}$ on the 28th of May. IMF Bz also turned southward, reaching a minimum value of $-19.71 \mathrm{nT}$ at 2340 UT. During this period, PCN and PCS indices 
attained peak values of about $9.0 \mathrm{mV} / \mathrm{m}$, while AE reached peak values of about $1700 \mathrm{nT}$. SYM-H gradually increased on the 29th of May to about $-5 \mathrm{nT}$, it thereafter decreased to $-39 \mathrm{nT}$ at $1900 \mathrm{UT}$. This period corresponded to the second southward turning of IMF Bz with a minimum value of -13.11 nT. There were also noticeable features on PCN, PCS and AE indices at 1230 UT on the 29th of May. The storm finally recovered on the 31 st of May.

The zoomed plots of PCN, PCS, AE indices, ASYM-H and variations of Diono over Guam, Mbour and Kourou from 27-29th May, 2017 are shown in Figure 3(a-d). On the 27th of May, when the forward shock arrived at the Earth's magnetosphere, an increase in Diono occurred only at Kourou. Oscillations in Diono with minima values of $-10.17 \mathrm{nT},-28.86 \mathrm{nT}$ and $-46.29 \mathrm{nT}$ for Guam, Mbour and Kourou, respectively within 2000-0000 UT. On the day of the storm's main phase (28th of May), Diono reached three minima values: $-60.19 \mathrm{nT},-51.79 \mathrm{nT}$ and $-46.66 \mathrm{nT}$ within 0400-1020 UT (1400-2020 LT) at Guam and peaked to the positive at Mbour and Kourou. Later, minima values of $37.96 \mathrm{nT}$ and $-12.99 \mathrm{nT}$ were recorded at about $1332 \mathrm{UT}$ at Mbour (1332 LT) and Kourou (1032 LT). On the 29th of May, Diono exhibited some fluctuations with minima values at about 1200-1800 UT at the three stations (2200-0400 LT at Guam; 1200-1800 LT at Mbour and 0900-1500 LT at Kourou). Small variations in the magnetospheric pressure were very evident in PC, AE and ASYM-H measurements. A typical case was the obvious rise in amplitudes of the PC, AE and ASYM-H during daytime on the 29th May, 2017. Figure 4(a-d) shows the DP2 and Ddyn plots for Kourou, Mbour and Guam for 27-29th May, 2017. DP2 fluctuated during the main phase of the storm with short periods of less than an hour. The IMF Bz sharply turned southward around 2200 UT on the 27th of May, 2017, heralding the onset of the storm's main phase. DP2 signatures were negative at 2200 UT, while Ddyn signatures were characterized with long periods of almost 24 hours. Consequently, Ddyn signatures play no major role during the main phase of the storm. There were also corresponding rise in auroral and polar cap indices at the onset of the main phase of the storm.

Figure 5(a-j) shows the daily variations of TEC (red lines), monthly mean quiet TEC (black lines) and TEC standard deviation (cyan area) from 23rd May-2nd June, 2017 over the Pacific Ocean (PFO) Asian longitude (Solomon Island [solo] and Guam [guug]); Indian Ocean (IDO) longitude (Port Blair [pbri] and Republic of Seychelles [sey2]); Atlantic Ocean (ATO) longitude (Ascension Island [ascg] and Dakar [dakr]) and the Pacific Ocean (PFO) American longitude (Galapagos [glbs], Tahiti [faa1], Mauna Kea [mkea], and Cook Island [ckis]). TEC at the two stations over the Pacific Asian longitude experienced positive responses to the storm. The main phase of the storm was around $0800 \mathrm{UT}$, corresponding to local sunset hours, 1900 LT at Solomon Island and 1800 LT at Guam. On the day of the storm's main phase (28th of May), a peak in TEC was observed at about 0340 UT (1440 LT) and 0620 UT (1620 LT) at Solomon Island and Guam, respectively. Over the Indian Ocean longitude, TEC responded positively to the storm. The time of occurrence of the storm's main phase corresponds 
to $1330 \mathrm{LT}$ and $1100 \mathrm{LT}$ at Port Blair and Seychelles, respectively. Over the Atlantic Ocean longitude, TEC responded positively to the storm at Ascension Island and negatively at Dakar. At these two stations, UT = LT. The peak in TEC occurred at 1415 LT at Ascension Island, while a slight reduction in TEC was observed at Dakar. At the Pacific Ocean American longitude, TEC responded positively to the storm. The time of occurrence of the storm's main phase corresponds to local sunset hours. A slight peak of TEC was observed over Galapagos at 2214 UT (1614 LT) but very pronounced at Tahiti, Mauna Kea and Cook Island. Figure 6(a-c) shows the global daily variations of SWARM A TEC on the 24th, 28th of May and 1st of June, 2017. 24th of May and 1st of June were quiet days with clear quiet TEC conditions. However, on the day of the storm's main phase, 28th of May, TEC enhancements were observed. TEC enhancements were prevalent over the Pacific Ocean American and Pacific Ocean Asian longitudes and least over the Atlantic Ocean longitude. Figure 7(a-j) shows the behaviour of ionospheric irregularities from 23rd May-2nd June, 2017. Irregularities were not obvious over all the stations from 23-27th of May. On the 28th May, irregularities occurred over the Pacific Asian and American sectors. From 29th May-2nd of June, irregularities were again not conspicuous over all the stations. In terms of intensity, they were weaker over Guam and Galapagos and stronger over Tahiti, Mauna Kea, Cook Island and Solomon Island on the day of the storm's main phase (28th May). Figure $8(\mathrm{a}-\mathrm{c})$ shows the sea surface temperature during the May 2017 storm and for two days outside the storm. Sea surface temperature were higher over the Pacific Ocean Asian longitude, and lower over the Pacific Ocean American longitude, particularly, region very close to the South American coastlines.

\subsection{8th September, 2017 GS event}

Figure $9(\mathrm{a}-\mathrm{e})$ shows variations of $\mathrm{V}_{\mathrm{x}}(\mathrm{km} / \mathrm{s}), \mathrm{IMF} \mathrm{Bz}(\mathrm{nT}), \mathrm{PCN}$ and PCS indices $(\mathrm{mV} / \mathrm{m})$, SYM-H (nT) and AE index (nT) from 3-13th September, 2017. The first CME released from the solar environment on the 4th of September at 1900 UT arrived at the Earth magnetosphere on the 7th of September in the morning [Tassev et al., 2017] as seen in the SSC. During this time, $\mathrm{V}_{\mathrm{x}}$ and IMF Bz increased abruptly. IMF Bz thereafter, turned southward with a value of $-10.56 \mathrm{nT}$ at about $0551 \mathrm{UT}$. The second CME arrived at the Earth at about 2330 UT on the 7th of September (vertical dash-lines). This storm is a dual-peak storm [Gonzalez et al., 1990]. SYM-H decreased to reach a minimum value of $-132 \mathrm{nT}$ at $0100 \mathrm{UT}$ on the 8th of September, signifying the first minimum peak of the storm. From the time of the arrival of the second forward shock to the time of minimum decrease in SYM-H, $V_{x}$ increased from $465.6 \mathrm{~km} / \mathrm{s}$ to $701.0 \mathrm{~km} / \mathrm{s}$, while IMF Bz went southward again with a minimum value of $-31.05 \mathrm{nT}$, and the corresponding PCN and PCN indices attained peak value of $20.0 \mathrm{mV} / \mathrm{m}$. AE recorded peak value of over $2500 \mathrm{nT}$. As the storm attempted to recover, a third southward turning of IMF Bz with a minimum value of $-17.48 \mathrm{nT}$ occurred at $1200 \mathrm{UT}$ on the 8 th of September. The corresponding PCN and PCN indices attained peak value of $17.55 \mathrm{mV} / \mathrm{m}, \mathrm{AE}$ recorded peak values of over $2500 \mathrm{nT}$. SYM-H again decreased to $-109 \mathrm{nT}$ at $1800 \mathrm{UT}$ (second minimum peak of the storm). 
On the 12th of September, $V_{x}$ increased to $625.5 \mathrm{~km} / \mathrm{s}$ and IMF Bz turned southward for the fourth time with a minimum value of $-11.79 \mathrm{nT}$. Around 2300 UT, PCN and PCN indices attained peak value of about $9.54 \mathrm{mV} / \mathrm{m}$. AE recorded peak values of over $1000 \mathrm{nT}$. SYM-H reached a value of -53 nT at 0010 UT on the 13th of September.

The zoomed plots of PCN, PCS, AE indices, ASYM-H and variations of Diono over Guam, Mbour and Kourou from 3-13th of September, 2017 are shown in Figure 10(a-d). An increase in Diono was observed at Mbour (1200 LT) and Kourou (0900 LT) at about 1200 UT on the 6th of September and 1445 UT (1445 LT at Mbour and 1145 LT at Kourou) on the 7th of September. This was not noticeable over Guam because of local time effect (early morning hours). In the early hours of 8th September at about 0030 UT (1030 LT at Guam, 0030 LT at Mbour and 2130 LT at Kourou), a sharp increase in Diono of magnitude $28.31 \mathrm{nT}, 103.9 \mathrm{nT}$ and $38.87 \mathrm{nT}$ occurred at the three magnetometer stations, respectively. This was followed by a decrease to a minimum of $-47.35 \mathrm{nT}$ at about $0200 \mathrm{UT}$ (1200 LT) over Guam only. From noon to post-noon hours, Diono fluctuated with minimum values of $-43.32 \mathrm{nT}$ at $1530 \mathrm{UT}$ (0130 LT) at Guam; -112.2 nT at $1430 \mathrm{UT}$ (1430 LT) at Mbour; and -70.42 nT at 1513 UT (1213 LT) at Kourou. On the 10th of September, the three magnetometer stations experienced some enhancements in Diono at about 1610 UT (0210 LT at Guam, 1610 LT at Mbour and 1310 LT at Kourou). Figure 11(a-d) shows the DP2 and Ddyn plots for Kourou, Mbour and Guam for 7-9th September, 2017. DP2 fluctuated during the main phase of the storm. The IMF Bz sharply turned southward around 2200 UT on the 7th of September, 2017, heralding the onset of the storm's main phase with short periods of less than an hour. DP2 signatures were negative around 2100 UT, while Ddyn signatures were characterized with long periods of almost 24 hours. Consequently, Ddyn signatures play no major role during the main phase of the storm. There were also corresponding rise in auroral and polar cap indices at the onset of the main phase of the storm.

Figure 12(a-1) shows the daily variations of TEC, monthly mean quiet TEC and TEC standard deviation from 3-13th September, 2017 over the Pacific Ocean (PFO) Asian longitude (Solomon Island [solo] and Namria General Santos [pgen]); Indian Ocean (IDO) longitude (Diego Garcia [dgar] and Seychelles [sey2]); Atlantic Ocean (ATO) longitude (Ascension Island [ascg], Dakar [dakr], Fortaleza [brft], Kourou [koug]); and the Pacific Ocean (PFO) American longitude (Risiketea [gamb], Tahiti [faa1], Mauna Kea [mkea] and Cook Island [ckis]). TEC responded positively to the storm at the two stations on the Pacific Ocean Asian longitude. The main phase of the storm occurred at 1800 UT, corresponded to early morning hours over the Pacific Ocean Asian longitude. On the 7th of September, the highest enhancement occurred around midnight of 7th September and noon-time of 8th September. Sharp TEC enhancement was also observed in the midnight to post-midnight period of 9-10th September. In Namria General Santos the enhancement was observed from early morning to post-noon of 8th September, while on the 9th of September, enhancement was seen from early 
morning up to about 0600 UT (1400 LT). Over the Indian Ocean longitude, the influences of the storm on TEC were not noticeable at Seychelles on the day of the storm's main phase. There were data gaps on the 8th of September at Diego Garcia. The time of occurrence of the storm's main phase corresponded to post sunset hours at this longitude. Over the Atlantic Ocean longitude, TEC responded positively to the storm. The time of occurrence of the storm's main phase corresponded to daily active solar period: 1400 and 1500 LT at Fortaleza and Kourou, respectively and 1800 LT at Dakar and Ascension Island. Over the Pacific Ocean American longitude, TEC responded positively to the storm. The time of occurrence of the storm's main phase corresponded to local sunset hours. Figure 13(a-c) shows the global daily variations of SWARM A TEC for 4th, 8th and 12th of September, 2017. Surprisingly, despite the fact that 4th of September was a magnetic quiet day, TEC enhancements were generally observed over the oceanic longitudes. These enhancements were most prevalent over the Pacific Ocean Asian and Pacific Ocean American longitudes, followed by the Indian Ocean longitude and least over the Atlantic Ocean longitude. 12th of September was a quiet day with obvious quiet TEC condition. On the day of the storm's main phase, 8th of September, TEC enhancements were prevalent over the Pacific Ocean Asian, Pacific Ocean American and the Atlantic Ocean longitudes and least over the Indian Ocean longitude.

Figure 14(a-1) shows the variations of irregularities from 3-13th of September, 2017 over the GNSS stations. Over Solomon Island and Namria General Santos in the Pacific Ocean Asian longitude, there were no noticeable irregularities from 3-13th of September, except on the 8th of September. Namria General Santos had data gaps on the 7th of September, 2017. Over the Indian Ocean longitude, irregularities were not noticeable over Diego Garcia Island and Seychelles. There were data gaps in Diego Garcia on the 8th of September. Over the Atlantic Ocean longitude, ROTI values were low from 3-12th of September at Ascension Island. In the early hour on the 13th of September, ROTI increased, signifying post-midnight irregularities occurrence. Over Dakar, four out of five days before the storm recorded irregularities and on the day of the storm's main phase, 8th of September, irregularities were not conspicuous. The irregularities remained absent on the 9th of September but reappeared on the 10,12 and 13th of September. Fortaleza experienced early morning irregularities on the 6th of September and midnight irregularities on the 7th of September before the storm's main phase. On the 8 and 9th of September, no irregularities occurred. However, midnight irregularities reappeared from 10-13th of September. Kourou only experienced midnight irregularities on the 7, 11 and 12th of September. From 3-13th of September, there were no irregularities over all the stations in the Pacific Ocean American longitude. Figure 15(a-f) shows the sea surface temperature and the sea level anomaly during the September 2017 storm and for other two days outside the storm. Sea surface temperature and sea level anomaly were also higher over the Pacific Ocean Asian longitude, and lower over the Pacific Ocean American longitude. 


\section{Discussion}

The two storms were caused by CME transients, i.e., manifestations of magnetic fields reconfigurations driven by magnetic reconnections [Dungey, 1961] at the Sun's coronal surface. The arrival of CMEs at the magnetosphere created the observed fast forward shocks that led to the SSCs for both storms (Figures 2 and 9). CME transient has two components, namely, magnetic cloud (a magnetic flux rope) [Burlaga et al., 1981, Lepping et al., 1990, 2015] and turbulent magnetic field regions (sheath regions) [Guo et al., 2011]. These regions are usually sandwiched in-between shocks and the leading edges of CMEs. Specifically, the storm of 28th of May, 2017 was driven by sheath and magnetic cloud fields, while the storm of 8th of September, 2017 was driven by sheath fields.

The transit of solar eruptions from solar surface to the Earth's magnetosphere usually leads to transfer of energy into the magnetosphere [Sckopke, 1966]. During the occurrences of the two storms, there were enhancements in auroral currents (Figures 3 and 10). The influence of these high auroral currents manifested clearly in the enhancements of the observed auroral/high latitude TEC measurements by SWARM A satellite (Figures 6 and 13), particularly, over the Pacific Ocean American and Pacific Ocean Asian longitudes. Electric currents at auroral latitudes get enhanced by precipitating particles, field aligned currents and convection of magnetospheric electric field via Joule heating and momentum transfer by the Ampere force. Joule heating leads to transfer of energy to the neutrals, while Ampere force moves neutral wind by momentum transfer. Both processes drive thermospheric wind [Richmond and Roble, 1979; Sharma et al., 2011], which could extend from the high- to middle- and low latitudes [Mazaudier et al., 1985, Nava et al., 2016]. These winds drag ionization to altitudes where recombination rates are significantly reduced, thereby causing enhancements in TEC, electron plasma density and other ionospheric parameters. These winds are responsible for global changes in thermospheric composition [Fuller-Rowell et al., 1994] and they are longitudinal dependent [Jones, 1971, Prolss, 1995].

For the 28th May, 2017 storm, IMF Bz sharply turned southward around 2300 UT on the 27th of May, 2017 to herald the onset/SSC of the storm and caused SYM-H to rise suddenly in the positive direction (Figure 2). The convection current also increased correspondingly during the time of the storm onset (Figure 3). At the storm onset, Diono increase over the Pacific Ocean Asian longitude and decreased over the Atlantic Ocean longitude but reversed in orientation during the main phase of the storm, positive over the Atlantic Ocean longitude and negative over the Pacific Asian Ocean longitude. At 2300 UT, DP2 signatures fluctuated into negative (eastward) direction, while Ddyn signatures were characterized with longer-hours periods at the three magnetometers stations (Figure 4). 2300 UT corresponds to 2000 LT (nighttime) at Kourou, 2300 LT (nighttime) at Mbour, and 0900 LT (daytime) at Guam. Kourou and Mbour are located over the Atlantic Ocean longitude, while Guam is located over the Pacific Ocean Asian longitude. It is worthy to note that 2300 LT 
corresponds to around 1200-1300 LT (daytime) over the Pacific Ocean American longitude. SYM-H gradually decreased, reaching a minimum value of $-145 \mathrm{nT}$ at $0800 \mathrm{UT}$ on the 28th of May. $0800 \mathrm{UT}$ corresponds to 2100-2200 LT (post-sunset) over the Pacific Ocean American longitude, 0500-0800 LT (early morning) over the Atlantic Ocean longitude, 1100-1300 LT (daytime) over the Indian Ocean longitude and 0400-0500 LT (early morning) over the Pacific Ocean Asian longitude. During storms, high latitudes electric fields, when sufficiently large do penetrate promptly into the low latitude ionosphere [Nishida, 1968]. This electric field, termed PPEF [Vasyliunas, 1970; Senior and Blanc, 1984] is eastward and westward in the dayside and night-side, respectively [Hanson and Moffett, 1966, Abdu, 2012, Abdu et al., 1997]. Short-term oscillations of Diono with a period around 30 minutes to roughly lesser than 3 hours, during southward turning of IMF Bz were very evident in DP2. DP2 are signatures of PPEF, while Ddyn are signatures of DDEF [Nishida et al., 1966, Hairston et al., 2016, Amory-Mazaudier et al., 2017].

In the Pacific American longitude, during daytime, Tahiti (-16.42 $\mathrm{dip})$ and Cook Island $\left(-21.61^{\circ} \mathrm{dip}\right)$ recorded conspicuous increase in TEC, maximum TEC at $1730 \mathrm{LT}$ and $1756 \mathrm{LT}$, respectively. Galapagos (9.46 dip) and Mauna Kea (20.53 dip) recorded comparatively lesser enhancements in TEC, maximum TEC at about 1315 LT and 1315 LT, respectively (Figure 5). Over Solomon Island and Guam in the Pacific Ocean Asian longitude, enhancements in TEC were also observed. Over the Indian Ocean and Atlantic Ocean longitudes, being in the night-side during the storm onset, the storm occurrence did not cause significant influence in TEC over the two longitudes. The enhancements in TEC were due to the eastward PPEF that occurred in the daytime. During daytime storm's onset, under southward turning of IMF Bz, eastward PPEF enhances low latitude ionospheric electrodynamics [Kikuchi et al., 1996]. The observed response of the ionosphere over the Pacific American longitude was an indication of a strong fountain effect that gave rise to increase in ionization over the crests (Tahiti, $-16.42^{\circ}$ dip and Cook Island, $-21.20^{\circ}$ dip). However, Mauna Mkea (20.53 dip) experienced lower enhancement in TEC compared to TEC observations at Tahiti and Cook Island. This was a clear indication of asymmetry in the redistribution of plasma over the northern and southern crests of the EIA during the disturbance [Huang et al., 2012, Immel and Mannиссі, 2013]. The hemispherical asymmetry in plasma distribution is attributable to the effects of neutral winds [Zaourar et al., 2017]. Over the Atlantic African longitude, Dakar (5.88 dip) located at the trough of the EIA experienced TEC reduction while Ascension Island (-16.09 $\mathrm{dip})$ located toward the crest of the anomaly in the southern hemisphere experienced enhancement in TEC. Sufficiently increase in electric fields caused vertical upwelling of $E \times B$ drift which in turn moved ionization to the EIA crests. During the recovery phase of this storm, Ddyn still fluctuated while the amplitudes of DP2 reduced significantly. Ddyn are the signatures of DDEF, resulting from disturbance wind driven by auroral heating [Blanc and Richmond, 1980; Le Huy and Amory-Mazaudier, 2005; Fathy et al., 
2014]. DDEF is opposite in configuration to PPEF and longer in period (in the order of days), as such reduced TEC during the recovery phase of storms.

The 8th September, 2017 daytime has a unique characteristic of two-step main phase. The arrival of the first shock was around the midnight of 6th of September. The second shock arrived almost at midnight of 7th of September but the IMF Bz turned sharply southward around 2200 UT on the 7th of September, 2017 to herald the onset/SSC of the daytime and caused SYM-H to rise suddenly in the positive direction (Figure 9). The convection current also increased correspondingly during the time of the storm onset (Figure 10). At the storm onset, Diono increased at Kourou, and decreased at Mbour and Guam but reversed in orientation during the main phase of the storm, positive over Mbour and Guam, and negative over Kourou. At the storm onset, DP2 signatures fluctuated into negative direction, while the Ddyn signatures were characterized with longer-hours periods at the three magnetometers stations (Figure 11). 2200 UT corresponds to 1900 LT (post-sunset hours) at Kourou, 2200 LT (post-sunset/nighttime) at Mbour, and 0800 LT (daytime) at Guam. This time corresponds to around 1100-1200 LT (daytime) over the Pacific Ocean American longitude. SYM-H gradually decreased to $-132 \mathrm{nT}$ at $0100 \mathrm{UT}$ on the 8th of September, 2017. 0100 UT corresponds to 1400-1500 LT (daytime) over the Pacific Ocean American longitude, 2300-0100 LT (nighttime) over the Atlantic Ocean longitude, 0400-0600 LT (early morning) over the Indian Ocean longitude and 11001200 LT (around midday) over the Pacific Ocean Asian longitude

TEC enhancements were observed over the Pacific Ocean Asian and Pacific Ocean American longitudes (Figure 12). These two longitudes were in the dayside during the occurrence of PPEF. Surprisingly, Tahiti $\left(-16.42^{\circ}\right)$ experienced comparatively lower enhancements in TEC over the Pacific Ocean American longitude. This could be an indication that the crest of the EIA in the southern hemisphere of this sector had moved ahead of Tahiti $\left(-16.42^{\circ}\right)$ by super fountain effect. Perhaps, PPEF was intensified in the southern crest of the EIA anomaly over the Pacific Ocean American longitude to give rise to super fountain effect. In the Indian and Atlantic Oceans longitudes, where the time of occurrence of PPEF coincided with local post-sunset hours, enhancements in TEC were not very noticeable. The recovery phase commenced with the northward returning of $\mathrm{Bz}$ on the 9th of September and maintained quiet values until 12th of September. Diono increased with several fluctuations and minima. DDEF has been reported to be responsible for reduction in TEC in the dayside during the recovery phases of geomagnetic storms because of their westward orientation [Tsurutani et al., 2004]. During the recovery phase of the September storm, reduction in TEC was observed at Ascension Island on the 10-11th September. TEC enhancements were seen during the recovery phase of the storm in Solomon Island and Namria General Santos in the Pacific Ocean Asian longitude. Furthermore, during this event, a slight increase in TEC was observed some days before the storm (3-5th of September), mostly over the Pacific Ocean Asian and Pacific Ocean American 
longitudes. The increase in TEC was very obvious on the 4th of September (Figure 13). The enhancement in TEC observed on the 4-6th of September, despite the fact that these days were magnetically quiet days might be attributed to the solar flares that occurred during the period (www.spaceweather.com). As reported by Yasyukevich et al. [2018], these flares were accompanied by solar radio bursts, leading to increase in TEC. It is well known that X-rays and Extreme Ultra Violet (EUV) radiation have the capacity of increasing ionization in the ionosphere, especially on the dayside [Mitra, 1974, Tsurutani et al., 2009, Yan et al., 2018].

Generally, over the equatorial/low latitude region, post-sunset eastward Pre-Reversal Enhancement (PRE) of $E \times B$ drift supports the uplifting of F-layer altitude to create conducive environment where irregularities can be generated through the Rayleigh Taylor Instability (RTI) process [Abdu et al., 1995, Akala et al., 2014, 2016]. However, if the electric fields are westward during post-sunset hours in the region, the uplifting of $E \times B$ drifts is prevented, consequently, irregularities generation is inhibited. For the May, 2017 storm, irregularities were observed on the days before and after the day of the main phase of the storm. During the main phase of the storm, irregularities were triggered over stations located in the Pacific Ocean American longitude (Figure 7). The main phase of the storm occurred at a period that corresponded to post-sunset hours at this longitude, the hours of the day which supports PRE generations. The generated PREs might have strengthened $E \times B$ drift, thereby lifting the F-layer to altitude where the formation of irregularities was favourable [Sultan, 1996, Amaechi et al., 2018a]. For the September, 2017 storm, irregularities were not conspicuous over all the longitudes (Figure 14). The times of the storm's onset and the storm main phase coincided with early morning, daytime and nighttime hours over all the longitudes. These hours do not support PRE generation. Consequently, irregularities were not observed over the longitudes. The irregularities inhibition on the 8th of September was driven by westward electric fields (DDEF). Over the Atlantic Ocean longitude, irregularities were present on the 7 and 10-11th of September; they were triggered by the eastward PPEF associated with the second turning of IMF Bz [Huang et al., 2017].

Finally, we also analyzed the observed pattern of irregularities distributions during the study period from the perspective of large-scale atmospheric circulation along the longitude-height plane over the equatorial Pacific Ocean (Walker Circulation) [Lau and Yang, 2015]. Walker Circulation features low-level winds blowing from east to west across the central Pacific Ocean, raising dynamics over the warm water of the western Pacific Ocean. The circulation is usually driven by the gradient of sea surface temperature along the equator, leading to coupling processes between tropical atmosphere and oceans. The warming of the western Pacific Ocean increases water vapour, latent heat, and upward motion in the atmosphere. The two phenomena which modify the annual air mass circulation of the Pacific Ocean are the El Nino Southern Oscillation (ENSO) and Madden Julian Oscillations (MJO) [Zeng and Pyle, 2005, Zhang, 2005]. Both play significant roles in changing the air mass circulation over the entire Pacific Ocean and invariably, causing changes in air mass transport in the atmosphere. 
ENSO has two phases, namely, negative (El Nino) and positive (La Nina). El Nino involves anomalously warm sea surface temperatures, in the eastern and central Pacific Oceans which produces large changes in evaporation and latent heat transfer to the atmosphere [Zeng and Pyle, 2005].

The sea temperature anomaly causes the warmest sea surface temperature and convection that are normally found in the western Pacific Ocean at the expense of the eastern Pacific Ocean (Figure 8 and 15). These often lead to variations in surface pressure between the western and eastern Pacific Oceans. Low pressure is shifted from the western Pacific and Indian Oceans to the central and eastern Pacific Oceans. During El Nino, low pressure is anomalously low over the central and eastern Pacific Oceans, whereas the western Pacific Ocean experiences anomalously high pressure. The opposite phase of the EL Nino is La Nina with anomalously low pressure over the Indian Ocean and western Pacific Ocean and anomalously high over the central and eastern Pacific Ocean [Zeng and Pyle, 2005]. The dominance of intensity of TEC over the eastern and western Pacific Oceans manifested clearly in our data (Figures 6 and 13). Furthermore, intensities of TEC were generally higher over the oceans than over the landlocked regions. We recorded stronger irregularities over the western Pacific Ocean longitude during the time when the sea surface temperature was significantly reduced. Negative sea surface temperature anomaly increases the wind system in the entire atmosphere and non-migrating waves in the upper atmosphere. This could have in turn enhanced ionospheric dynamo electric field. It is important to point out that the data used for the current analysis only spanned for a period of eleven days; five days before the main phase of each storm, and five days after, in addition to the day of the main phase of the storm. For this reason, to strengthen the conclusion on the possible influences of the ocean on the ionosphere, future analyses of large volume of data over long period of time are recommended.

\section{Conclusions}

This work investigated the responses of the equatorial/low latitude ionosphere over the global oceanic regions to geomagnetic storms of May and September, 2017. We concluded that:

1. Both storms were caused by CME transients. A positive storm effect in TEC caused by eastward PPEF was observed over most of the longitudinal sectors on the day of the first storm (28th May, 2017). The largest and long duration enhancements were recorded over the Pacific Ocean American longitude. PPEF also intensified the southern crest of the anomaly over the Pacific Ocean American longitude. The responses of TEC over the Indian Ocean and Atlantic Ocean longitudes were mild. The longitudinal dependence of PPEF is premised on its local time of storm occurrence.

2. For the 8th September, 2017 storm, the observed enhancements in TEC over the Pacific Ocean Asian and Pacific Ocean American longitudes were in response to PPEFs. Large enhancements in TEC with characteristic double peak were observed over the Pacific Ocean American longitude. TEC 
responses to the storm were generally low over the Atlantic Ocean and Indian Ocean longitudes because of the local time effects of PPEF. TEC enhancements observed on the 4-6th of September, geomagnetic quiet days were associated with the solar flares occurrences [Tassev et al., 2017, Lei et al., 2018]. Furthermore, DDEFs generally manifested by weak Ddyn signatures after the main phases of the two storms were responsible for positive ionospheric responses during the recovery phases of the storms.

3. The first storm triggered irregularities over the Pacific Ocean longitude during lager PC and AE currents within 0700-1200 UT (for instance, this time range corresponds to 1830-2330 LT at Tahiti and 1300-1800 LT at Galapagos) on the storm day. This time range is the period for PREs, a time conducive for irregularities generation. For the second storm, irregularities were inhibited by westward DDEF occurrence during daytime morning/afternoon. This westward electric field cancels the PRE eastward electric field; hence hindering the generation of irregularities. These results validated model results by Blank and Richmond [1980] and Fejer et al. [2008]. Furthermore, our results are in agreement with earlier results by Nayak et al. [2016a, b] and Amaechi et al. [2018a].

4. The intensity of sea surface temperature and pressure has dependence on ionospheric TEC and irregularities. Our results showed that intensities of TEC were higher over the oceans than over the landlocked regions. The coupling between the ocean and the atmosphere, especially over the Pacific Ocean Asian and American longitudes has a relation with Walker's circulation. Walker's circulation modifies the convection motions of the atmosphere. Atmospheric convection generates non-migrating tides propagating at the altitudes of the ionosphere and modifying the atmospheric circulation and as a consequence, influencing the dynamo electric field and invariably, ionospheric irregularities generation.

\section{Acknowledgments}

The ACE solar wind and IMF data were obtained at https//omniweb.gsfc.nasa.gov/hw/hmtl. Dst and auroral indices data were obtained at www.wdc.kugi.kyoto-u.ac.jp. UNAVCO provided the GPS TEC data at htpp://www.unavco.org/data/data.html, the magnetometer data were obtained at https://www.intermagnet.org/data-donnee/data-eng.php. The international quiet days were obtained at ftp://ftp.gfz-potsdam.de. JASON-2 satellite sea level anomaly data were obtained at $\mathrm{ftp} / / / \mathrm{ftpcoastwatch.noaa.gov/pub/socd/lsa/johnk/coastwatch/j2} \mathrm{and} \mathrm{the} \mathrm{optimum} \mathrm{interpolation} \mathrm{sea} \mathrm{surface}$ temperature data were obtained at https://www.ncdc.noaa.gov/oisst. SWARM TEC data were obtained at ftp://swarm-diss.eo.esa.int/. The first author; AOA thanks The Abdus Salam International Centre for Theoretical Physics (ICTP), Trieste, Italy for the Regular Associate Award. This research was conceptualized during his visit to ICTP in February/March, 2019. AOA thanks Veronica P. Lance of NOAA/Center for Weather and Climate Prediction, Maryland for her useful discussion on JASON data processing. Waqar Younas of the Department of Physics, Quaid-i-Azam Universtiy, Islamabad, Pakistan provided the MATLAB codes to extract 
Ddyn and DP2 signatures from Diono. The authors also thank the editor and the reviewers for their useful comments and suggestions which have significantly improved this paper.

\section{References}

Abdu, M. A., Batista, I. S., Walker, G. O., Sobral, J. H. A., Trivedi, N. B., and de Paula, E. R. (1995). Equatorial ionospheric electric fields during magnetospheric disturbances: Local time/longitudinal structure and spread F: A case study from GUARA/EITS campaigns. Geophys. Res. Lett. 57(10), 1065-1083.

Abdu, M.A., Sastri, J.H., MacDougall, J., Batista, I.S., Sobral, J.H.A. (1997). Equatorial dynamo electric longitudinal structure and spread F: a case study from GUARA/EITS campaigns. Geophys. Res. Lett. 24(13), 1707-1710.

Abdu, M.A. (2012). Equatorial spread F/plasma bubble irregularities under storm time disturbance electric fields. J. Atmos. Sol.-Terr. Phys. 75-76, 44-56.

Akala, A. O., P. H. Doherty, C. E. Valladares, C. Carrano, and R. Sheehan (2011). Statistics of GPS scintillations over South America at three levels of solar activity, Radio Science, doi:10.1029/2011RS004678.

Akala, A. O., P. H. Doherty, C. S. Carrano, C. E. Valladares, and K. M. Groves (2012), Impacts of ionospheric scintillations on GPS receivers intended for equatorial aviation applications, Radio Science, RS4007, doi:10.1029/2012RS004995.

Akala A. O., A. B. Rabiu, E. O. Somoye, E. O. Oyeyemi, and A. B. Adeloye (2013a), The Response of African equatorial GPS-TEC to intense geomagnetic storms during the ascending phase of solar cycle 24, Journal of Atmospheric and Solar-Terrestrial Physics, doi/10.1016/j.jastp.2013.02.006, 98, 50-62.

Akala, A. O., G. K. Seemala, P. H. Doherty, C. E. Valladares, C. S. Carrano, J. Espinoza, and S. Oluyo (2013b), Comparison of equatorial GPS-TEC observations over an African station and an American station during the minimum and ascending phases of solar cycle 24, Ann. Geophys., 31(11), 2085-2096. doi:10.5194/angeo-31-2085-2013.

Akala, A.O., L.L.N. Amaeshi, P.H. Doherty, K.M. Groves, C.S. Carrano, C.T. Bridgwood, G.K. Seemala, E.O. Somoye, (2014), Characterization of GNSS scintillations over Lagos, Nigeria during the minimum and ascending phases (2009-2011) of solar cycle 24, Advances in Space Research, doi/10.1016/j.asr.2013.09.034, 53(1), 37-47

Akala, A. O., L.L.N. Amaeshi, E.O. Somoye, R.O. Idolor, E. Okoro, P.H. Doherty, K.M. Groves, C.S. Carrano, C.T. Bridgwood, P. Baki, F.M. D'ujanga, G.K. Seemala (2015), Climatology of GPS amplitude scintillations over equatorial Africa during the minimum and ascending phases of solar cycle 24, Astrophysics and Space Science, 357:17, DOI 10.1007/s10509-015-2292-9

Akala, A. O., A. Awoyele, and P. H. Doherty (2016), Statistics of GNSS amplitude scintillation occurrences over Dakar, Senegal, at varying elevation angles during the maximum phase of solar cycle 24, Space Weather, 14, 233-246, doi:10.1002/2015SW001261.

Akala, A. O., A.H. Ejalonibu, P.H. Doherty, S.M. Radicella, K.M. Groves, C.S. Carrano, C.T. Bridgwood, R.A. Stoneback (2017), Characterization of GNSS amplitude scintillations over Addis Ababa during 2009-2013, Advances in Space Research, 59. 1969-1983.

Akala A. O., E. O.Oyeyemi, O. A. Arowolo, P. H.Doherty (2019), Characterization of GPS and EGNOS Amplitude Scintillations over the African Equatorial/low-latitude Region, Advances in Space Research, 3062-3075, https://doi.org/10.1016/j.asr.2019.01.021

Amaechi, P.O., Oyeyemi, E.O., and Akala, A.O. (2018a). Geomagnetic storm effects on the occurrences of ionospheric irregularities over the African equatorial/low-latitude region. Adv. in Space Res. 61 (2018) 2074-2090.

Amaechi, P. O., Oyeyemi, E. O., and Akala, A. O. (2018b). The response of African equatorial/low-latitude ionosphere to 2015 St. Patrick's Day geomagnetic storm. Space Weather, 16, 601-618.

Amory-Mazaudier, C., Bolaji, O. S., and Doumbia, V. (2017). On the historical origins of the CEJ, DP2, and Ddyn current systems and their roles in the predictions of ionospheric responses to geomagnetic storms at equatorial latitudes. J. Geophys. Res. 122, 7827-7833.

Astafyeva, E., Zakharenkova, I., Hozumi, K., Alken, P., Coïsson, P., Hairston, M. R., \& Coley, W. R. (2018), Study of the equatorial and low-latitude electrodynamic and ionospheric disturbances during the 22-23 June 2015 geomagnetic storm using ground-based and space-borne techniques. J. Geophys. Res., 123, 2424-2440, https://doi.org/10.1002/2017JA024981

Azzouzi, I., Migoya-Orue, Y., Amory-Mazaudier, C., Fleury, R., Radicella, S. M., Touzani, A. 
(2015). Signature of solar event at middle and low and latitudes in the European-African sector, during geomagnetic storms, October 2013. Adv. in Space Res. 56(9), 2040-2055.

Blanc, M., and Richmond, A. (1980). The ionospheric disturbance dynamo. J. Geophys. Res. 85 (A4), 1669-1686.

Blewitt, G. (1990). An Automatic editing algorithm for GPS data. Geophys. Res. Lett. 17 (2), 199-202.

Burke, W.J., Gentile, L.C., Huang, C.Y., Valladares, C.E., S.Y. Su (2004), Longitudinal variability of equatorial plasma bubbles observed by DMSP and ROCSAT-1. J. Geophys. Res. 109, A12301. https://doi.org/10.1029/2004JA010583.

Burlaga, L.F., R. P. Lepping (1977), The causes of recurrent geomagnetic storms. Planetary and Space Sci., 25, 1151-1160.

Burlaga, L.F., E. Sittler, F. Mariani, R. Schwenn (1981), Magnetic loop behind an interplanetary shock: Voyager, Helios and IMP-8 observations. J. Geophys. Res, 86, 6673-6681.

Carter, B. A., E. Yizengaw, R. Pradipta, J. M. Retterer, K. Groves, C. Valladares, R. Caton, C. Bridgwood, R. Norman, and K. Zhang (2016), Global equatorial plasma bubble occurrence during the 2015 St. Patrick's Day storm, J. Geophys. Res. Space Physics, 121, 894-905, doi:10.1002/2015JA022194

Chakrabarty, D., Sekar, R., Narayanan, R., Devasia, C. V., and Pathan, B. M. (2005). Evidence for the interplanetary electric field effect on the OI $630.0 \mathrm{~nm}$ airglow over low latitude. J. Geophys. Res. 110, A11301.

Chapman, S., and Ferraro, V. C. A. (1931). New theory of magnetic storms. Terr. Magn. Atmos. Electr. 36, 77-97.

Ciraolo, L., Azpilicueta, F., Brunini, C., Meza, A., and Radicella, S.M. (2007). Calibration errors on experimental slant total electron content (TEC) determined with GPS. J. Geod. 81, 111120.

Dungey, J.W. (1961), Interplanetary magnetic field and the auroral zones. Physical Review Letters, 6, 47-48.

Fathy, I., Amory-Mazaudier, C., Fathy, A., Mahrous, A. M., Yumoto, K., and Ghamry, E. (2014). Ionospheric disturbance dynamo associated to a coronal hole: Case study 5-10 April 2010. J. Geophys. Res. 119, 4120-4133.

Fejer, B. G. (2011), Low Latitude Ionospheric Electrodynamics, Space Science .Rev. 158, 145-166, doi: 10.1007/s11214-010-9690-7

Fejer, B. G., and Scherliess, L. (1997). Empirical models of storm time equatorial zonal electric fields. J. Geophys. Res. 102(A11), 24047-24056.

Fejer, B. G., J. W. Jensen, and S.-Y. Su (2008), Seasonal and longitudinal dependence of equatorial disturbance vertical plasma drifts, Geophys. Res. Lett., 35, L20106, doi:10.1029/2008GL035584.

Forbes, J. M., M. E. Hagan, X. Zhang (2007), Seasonal cycle of nonmigrating diurnal tides in the MLT region due to tropospheric heating rates from the NCEP/NCAR Reanalysis Project, Adv. Space Res. 39, 1347-1350.

Fuller-Rowell, T. J., Codrescu, M. V., Moffett, R. J., and Quegan, S. (1994). Response of the thermosphere and ionosphere to geomagnetic storms. J. Geophys. Res. 99(A3), 3893-3914.

Gentile, L.C., Burke, W.J., F. J. Rich (2006), A climatology of equatorial plasma bubbles from DMSP 1989-2004. Radio Sci. 41, RS52S1. http://dx.doi.org/10.1029/2005RS003340.

Gentile, L.C., Burke, W.J., Roddy, P.A., Retterer, J.M., R.T. Tsunoda (2011), Climatology of plasma density depletions observed by DMSP in the dawn sector. J. Geophys. Res. 116, A03321. http://dx.doi.org/10.1029/2010JA016176.

Godin, O. A., N. A. Zabotin, and T. W. Bullett (2015), Acoustic-gravity waves in the atmosphere generated by infragravity waves in the ocean, Earth Planets Space, 67, 47, doi:10.1186/s40623-015-0212-4.

Gonzalez, W. D., A. L. C. Gonzalez and B. T. Tsurutani (1990), Dual-peak solar cycle distribution of intense geomagnetic storms. Planet. Space Sci. 38, 181-187.

Gonzalez, W., J. Joselyn, Y. Kamide, H. Kroehl, G. Rostoker, B. Tsurutani and V. Vasyliunas (1994), What is a geomagnetic storm? J. Geophy. Res., 99, 5771-5792.

Gopalswamy N, P. Mäkelä, H. Xie, S. Akiyama and S. Yashiro (2009), CME interactions with coronal holes and their interplanetary consequences. J Geophys Res., 114, doi: 10.1029/2008JA013686.

Gosling, J.T.,(1993), The solar flare myth, J. Geophys. Res., 98, 18, 937.

Gosling, J. T. and V. J. Pizzo (1999), Formation and evolution of corotating interaction regions and their three-dimensional structure. Space Sci. Rev. 89, 21.

Guo, J., X. Feng, B. A. Emery, J. Zhang, C. Xiang, F. Shen and W. Song (2011), Energy transfer during intense geomagnetic storms driven by interplanetary coronal mass ejections and their sheath regions. Journal of Geophysical Research 116, A05106.

Hagan, M. E., R. G. Roble, and J. Hackney (2001), Migrating thermospheric tides, J. Geophys. Res., 
106(A7), 12,739-12,752.

Hairston, M., Coley, W. R., and Stoneback, R. (2016). Responses in the polar and equatorial ionosphere to the March 2015 St. Patrick Day storm. J. Geophys. Res. 121, 11,213-11,234.

Hanson, W. B., and Moffett, R. J. (1966). lonization transport effects in the equatorial F region. J. Geophys. Res. 71(23), 5559-5572.

Hei, M.A., Heelis, R.A., J.P. McClure (2005), Seasonal and longitudinal variation of large-scale topside equatorial plasma depletions. J.Geophys. Res. 110, A12315. http://dx.doi.org/10.1029/2005JA011153.

Hickey, M. P., G. Schubert, and R. L. Walterscheid (2009), Propagation of tsunami-driven gravity waves into the thermosphere and ionosphere, J. Geophys. Res.: Space Physics, 114, A08304, doi:10.1029/2009JA014105.

Hickey, M. P., G. Schubert, and R. L. Walterscheid (2010), Atmospheric airglow fluctuations due to a tsunamidriven gravity wave disturbance, J. Geophys. Res.: Space Physics, 115, A06308, doi:10.1029/2009JA014977

Hofmann-Wellenhof, B., Lichtenegger, H., and Collins, J. (1994). Global Positioning Systems: Theory and practices. Springer-Verlag Wien.

Huang, C.S., M.R. Hairston (2015), The postsunset vertical plasma drift and its effects on the generation of equatorial plasma bubbles observed by the C/NOFS satellite. J. Geophys. Res. Space Phys. 120. http://dx.doi.org/10.1002/2014JA020735.

Huang, C. S., Sazykin, S., Chau, J. L., Maruyama, N., and Kelley, M. C. (2007). Penetration 1146. electric fields: Efficiency and characteristic time scale. J. Atmos. Sol.-Terr. Phys. 69(10-11), 1135-

Huang, C.-S., de La Beaujardiere, O., Roddy, P.A., Hunton, D.E.,Ballenthin, J.O., M.R. Hairston (2012), Generation and characteristics of equatorial plasma bubbles detected by the C/NOFS satellite near the sunset terminator. J. Geophys. Res. 117, A11313. http://dx.doi.org/10.1029/2012JA018163.

Huang, C.-S., de La Beaujardiere, O., Roddy, P.A., Hunton, D.E., Liu, J.Y., S.P. Chen (2014), Occurrence probability and amplitude ofequatorial ionospheric irregularities associated with plasma bubbles during low and moderate solar activities (2008-2012). J. Geophys. Res. Space Phys. 119, 1186-1199. http://dx.doi.org/10.1002/2013JA019212.

Immel, T.J., and Mannucci, A.J. (2013). Ionospheric redistribution during geomagnetic storms. J. Geophys. Res. 118, 7928-7939.

Jones, K. L. (1971). Electrodynamic drift effects in mid-latitude F-region storm phenomena. J. Atmos. Sol.-Terr. Phys. 33 (9) 1311-1319.

Kikuchi, T., H. Lühr, T. Kitamura, O. Saka, and K. Schlegel (1996), Direct penetration of the polar electric field to the equator during a DP2 event as detected by the auroral and equatorial magnetometer chains and the EISCAT radar. J. Geophys. Res. 101, 17,16117,173 .

Kil, H., Paxton, L.J., S.J. Oh (2009a), Global bubble distribution seen from ROCSAT-1 and its association with the evening pre-reversal enhancement. J. Geophys. Res. 114, A06307. http://dx.doi.org/10.1029/2008JA013672.

Kil, H., Oh, S.J., Paxton, L.J., T.W. Fang (2009b), High-resolution vertical E X B drift model derived from ROCSAT-1 data. J. Geophys. Res. 114, A10314. http://dx.doi.org/10.1029/2009JA014324.

Kintner, P. M., Ledvina, B. M., and De Paula, E. R. (2007). GPS and ionospheric scintillations. Space weather. 5(9).

Klobuchar, J. (1996), Ionospheric effects on GPS. Global Positioning System Theory and applications. 1, 485515 .

Komjathy, A., D. A. Galvan, P. Stephens, M. D. Butala, V. Akopian, B. Wilson, O. Verkhoglyadova, A. J. Mannucci, and M. Hickey (2012), Detecting ionospheric TEC perturbations caused by natural hazards using a global network of GPS receivers: The Tohoku case study, Earth Planets Space, 64, 1287-1294, doi:10.5047/eps.2012.08.003.

Kuai, J., Liu, L., Liu, J., Sripathi, S., Zhao, B., Chen, Y., et al. (2016). Effects of disturbed electric fields in the low latitude and equatorial ionosphere during the 2015 St. Patrick's Day storm. J. Geophys. Res. 121, 9111-9126.

Lau, K.-M. and S.Yang (2015), Walker Circulation: in Tropical Meteorology \& Climate, Encyclopedia of Atmospheric Sciences, 2nd Edition, 177-181, https://doi.org/10.1016/B978-0-12-382225-3.00450-3

Le Huy, M., and Amory-Mazaudier, C. (2005). Magnetic signature of the ionospheric disturbance dynamo at equatorial latitudes: "Ddyn". J. Geophys. Res., 110, A10301.

Lei, J., Huang, F., Chen, X., Zhong, J., Ren, D., Wang, W., Yue, X., Luan, X., Jia, M., Dou, X., 
Hu, L., Ning, B., Owolabi, C., Chen, J., Li, G., and Hu, L. (2018). Was Magnetic Storm the Only Driver of the Long-Duration Enhancements of Daytime Total Electron Content in the Asian-Australian Sector between 7 and 12 September 2017? J. Geophys. Res. 123(4), 32173232.

Lepping, R. P., J. A. Jones, L. F. Burlaga (1990), Magnetic Field Structure of Interplanetary Magnetic Clouds at 1 AU, J. Geophys. Res. 95(A8), 11,957-11,965.

Lepping, R. P., C. Wu and B. D. Berdichevsky. (2015), Yearly Comparison of Magnetic Cloud Parameters, Sunspot Number, and Interplanetary Quantities for the First 18 Years of the Wind Mission. Sol. Phys. 290, 553-578, doi:10.1007/s11207-014-0622-7.

Ma, G., and T. Maruyama (2003), Derivation of TEC and estimation of instrumental biases from GEONET in Japan. Ann. Geophys., 21,2083-2093. doi:10.5194/angeo-21-2083-2003

Makela, J. J., et al. (2011), Imaging and modeling the ionospheric airglow response over Hawaii to the tsunami generated by the Tohoku earthquake of 11 March 2011, Geophys. Res. Lett., 38, L13305, doi:10.1029/2011GL047860.

Mannucci, A. J., Wilson, B. D., and Edwards, C. D. (1993). A new method for monitoring the earth's ionosphere total electron content using the GPS global network. In: Proceedings of ION GPS- 93, Institute of Navigation. pp. 1323-1332.

Mazaudier, C., Bernard, R., and Venkateswaran, S. V. (1985). Correction to "Saint-Santin Radar observations of lower thermospheric storms". J. Geophys. Res. 90(A7), 6685-6686.

Mitra, A. P. (1974). Ionospheric effects of solar flares (p. 294). New York: Springer.

National Research Council (NRC) Report (2008), Severe Space Weather Events - Understanding Societal and Economic Impacts, The National Academies Press, Washington, DC, USA.

Nava, B., Rodríguez-Zuluaga, J., Alazo-Cuartas, K., Kashcheyev, A., Migoya-Orué, Y., Radicella, S. M., Amory-Mazaudier, C., and Fleury, R. (2016). Middle and low latitude ionosphere response to 2015 St. Patrick's Day geomagnetic storm. J. Geophys. Res. Space Physics, 121, 3421-3438.

Nayak, C., Tsai, L. C., Su, S. Y., Galkin, I. A., Tan, A. T. K., Nofri, E., and Jamjareegulgarn, P. (2016a). Peculiar features of the low-latitude and midlatitude ionospheric response to the St. Patrick's Day geomagnetic storm of 17 March 2015. J. Geophys. Res. 121(8), 7941-7960.

Nayak, C., Tsai, L.-C., Su, S.-Y., Galkin, I.A., Caton, R.G., Groves, K. M., (2016b), Suppression of ionospheric scintillation during St. Patrick's Day geomagnetic super storm as observed over the anomaly crest region station Pingtung, Taiwan: A case study, Adv. Space Res., 60(2), 396-405, http://dx.doi.org/10.1016/j.asr.2016.11.036.

Nishida, A. (1968). Geomagnetic DP2 fluctuations and associated magnetospheric phenomena. J. Geophys. Res. 73, 173.

Nishida, A., N. Iwasaki, and Nagata, N. T. (1966). The origin of fluctuations in the equatorial electrojet: A new type of geomagnetic variation. Ann. Geophys. 22, 478-484.

Occhipinti, G., L. Rolland, P. Lognonné, and S. Watada (2013), From Sumatra 2004 to Tohoku-Oki 2011: The systematic GPS detection of the ionospheric signature induced by tsunamigenic earthquakes, J. Geophys. Res.: Space Physics, 118, 3626-3636, doi:10.1002/jgra.50322.

Oladipo, A.O., and Schüler, T. (2013). Magnetic storm effect on the occurrence of ionospheric irregularities at an equatorial station in the African sector. Ann. Geophys. 56 (5), A0565.

Patra, A. K., Chaitanya, P. P., Dashora, N., Sivakandan, M., and Taori, A. (2016). Highly localized unique electrodynamics and plasma irregularities linked with the 17 March 2015 severe magnetic storm observed using multitechnique common-volume observations from Gadanki, India. J. Geophys. Res. 121(11).

Paznukhov, V. V., Carrano, C. S., Doherty, P. H., Groves, K. M., Caton, R. G., Valladares, C. E., et al. (2012). Equatorial plasma bubbles and L-band scintillations in Africa during solar minimum. Ann. Geophys. 30(4), 675-682.

Pi, X., Mannucci, A.J., Lindqwister, U.J., and Ho, C.M. (1997). Monitoring of global ionospheric irregularities using the worldwide GPS network. Geo. Res. Lett. 24 (18), 22832286.

Prölss, G. (1995). Ionospheric F-region storms, in Handbook of Atmospheric Electrodynamics, vol. 2, edited by H. Volland, pp. $195-248$, CRC Press, Boca Raton.

Richmond, A. D., and Roble, R. G. (1979). Dynamic effects of aurora-generated gravity waves on the mid-latitude ionosphere. J. Atmos. Sol.-Terr. Phys. 41(7-8), 841- 852.

Rostoker, G. (1972), Geomagnetic indices, Rev. Geophys. Space Phys., 10(4), 935-950.

Saito, S. (2013). Guidance on ionospheric scintillation observation in the low-latitude Region, Version 1.1b. In: International Civil Aviation Organization (ICAO), The Third Meeting of Ionospheric Studies Task

Force 
(ISTF/2), 15-17 October 2013, Seoul, Republic of Korea.

Sckopke, N. (1966), A general relation between the energy of trapped particles and the disturbance field near the Earth. Journal of Geophysical Research, 71(13), 3125-3130. https://doi.org/10.1029/JZ071i013p03125

Seemela, G.K. (2010), Rinex GPS-TEC program, version 1.45. satellite navig. sci and tech for Africa. In: Presentation at a Workshop held from 23rd March-9th April, 2009 at ICTP, Trieste, Italy.

Senior, C., and Blanc, M. (1984). On the control of magnetospheric convection by the spatial distribution of ionospheric conductivities. J. Geophys. Res. 89(A1), 261-284.

Sharma, S., Galav, P., Dashora, N., and Pandey, R. (2011). Longitudinal study of the ionospheric response to the geomagnetic storm of 15 May 2005 and manifestation of TADs. Ann. Geophys. 29(6), 1063.

Shimeis, A., I. Fathy, C. Amory-Mazaudier, R. Fleury, A. M. Mahrous, A. Yoshikawa, and K. Groves (2012), Signature of the coronal near the north crest equatorial anomaly over Egypt during the strong geomagnetic storm 5 April 2010. J. Geophys. Res. 117, A07309.

Sultan, P. J. (1996). Linear theory and modelling of the Rayleigh-Taylor instability leading to the occurrence of equatorial spread F. J. Geophys. Res. 101, (A12), 26875-26891.

Tassev, Y., Velinov, P. I., Tomova, D., and Mateev, L. (2017). Analysis of extreme solar activity in early september 2017: G4 - severe geomagnetic storm (07-08.09) and GLE72 (10.09) in solar minimum. Comptes rendus de l'Académie bulgare des Sciences, 70(10).

Tsurutani, B. T., W. D. Gonzalez, F. Guarnieri, Y. Kamide, X. Zhou, and J. K. Arballo (2004). Are high-intensity long-duration continuous AE Activity (HLDCAA) event substorm expansion events. J. Atmos. Sol.-Terr. Phys. 66,167-176.

Tsurutani, B. T., Verkhoglyadova, O. P., Mannucci, A. J., Lakhina, G. S., Li, G., and Zank, G. P. (2009), A brief review of "solar flare effects" on the ionosphere. Radio Sci. 44, RS0A17.

Tsurutani, B. T., Echer, E., Guarnieri, F. L., and Gonzalez, W. D. (2011), The properties of two solar wind high speed streams and related geomagnetic activity during the declining phase of solar cycle 23, J. Atmos. Solar-Terr. Phys., 73, 164, doi:10.1016/j.jastp.2010.04.003.

Valladares, C., Sheehan, R., Basu, S., Kuenzler, H., and Espinoza, J (1996), The multi-instrumented studies of equatorial thermosphere aeronomy scintillation system: Climatology of zonal drifts, J. Geophys. Res., 101, 26839-26850, doi:10.1029/96JA00183.

Vasyliunas, V. M. (1970), Mathematical models of magnetospheric convection and its coupling to the ionosphere: In Particules and fields in the magnetosphere, M. Mc Cormac \& D. Reidel (Eds.), pp. 60-71, Dordrecht, Netherlands: Springer.

Vasyliunas, V. M. (1972). The inter-relationship of magnetospheric processes: In Earth's magnetosphere processes, M. Mc Cormac \& D. Reidel (Eds.), pp. 29-38, Dordrecht, Netherlands: Springer.

Yan, X. L., Yang, L. H., Xue, Z. K., Mei, Z. X., Kong, D. F., Wang, J. C., and Li, Q. L. (2018). Simultaneous observation of a flux rope eruption and magnetic reconnection during an $\mathrm{X}$ class solar flare. The Astrophysical Journal Letters. 853(1), L18.

Yasyukevich, Y., Astafyeva, E., Padokhin, A., Ivanova, V., Syrovatskii, S., and Podlesnyi, A. (2018). The 6 September $2017 \mathrm{X}$-class solar flares and their impacts on the ionosphere, GNSS, and HF radio wave propagation. Space Weather, 16, 1013-1027.

Yizengaw, E., Moldwin, M. B., Mebrahtu, A., Damtie, B., Zesta, E., Valladares, C. E., and Doherty, P. (2011). Comparison of storm time equatorial ionospheric electrodynamics in the African and American sectors. J. Geophys. Res. 73, 156-163.

Yizengaw, E., and Groves, K. M. (2018). Longitudinal and Seasonal Variability of Equatorial Ionospheric Irregularities and Electrodynamics. Space Weather, 16(8), 946-968.

Zabotin,N.A., O. A. Godin, and T.W. Bullett (2016), Oceans are a major source of waves in the thermosphere, J. Geophys. Res.: Space Physics, 121, 3452-3463, doi:10.1002/2016JA022357.

Zaourar, N., Amory-Mazaudier, C., and Fleury, R. (2017). Hemispheric asymmetries in the ionosphere response observed during the high-speed solar wind streams of the 24-28 August 2010. Adv. in Space Res. 59(9), 2229-2247.

Zeng, G., and J. A. Pyle (2005), Influence of El Niño Southern Oscillation on stratosphere/troposphere exchange and the global tropospheric ozone budget, Geophys. Res. Lett., 32, L01814, doi:10.1029/2004GL021353.

Zhang, C. (2005), Madden-Julian Oscillation, Rev. Geophys., 43, RG2003, doi:10.1029/2004RG000158.

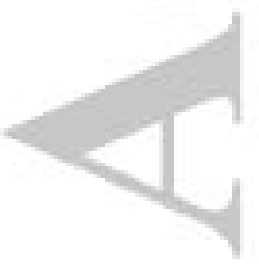




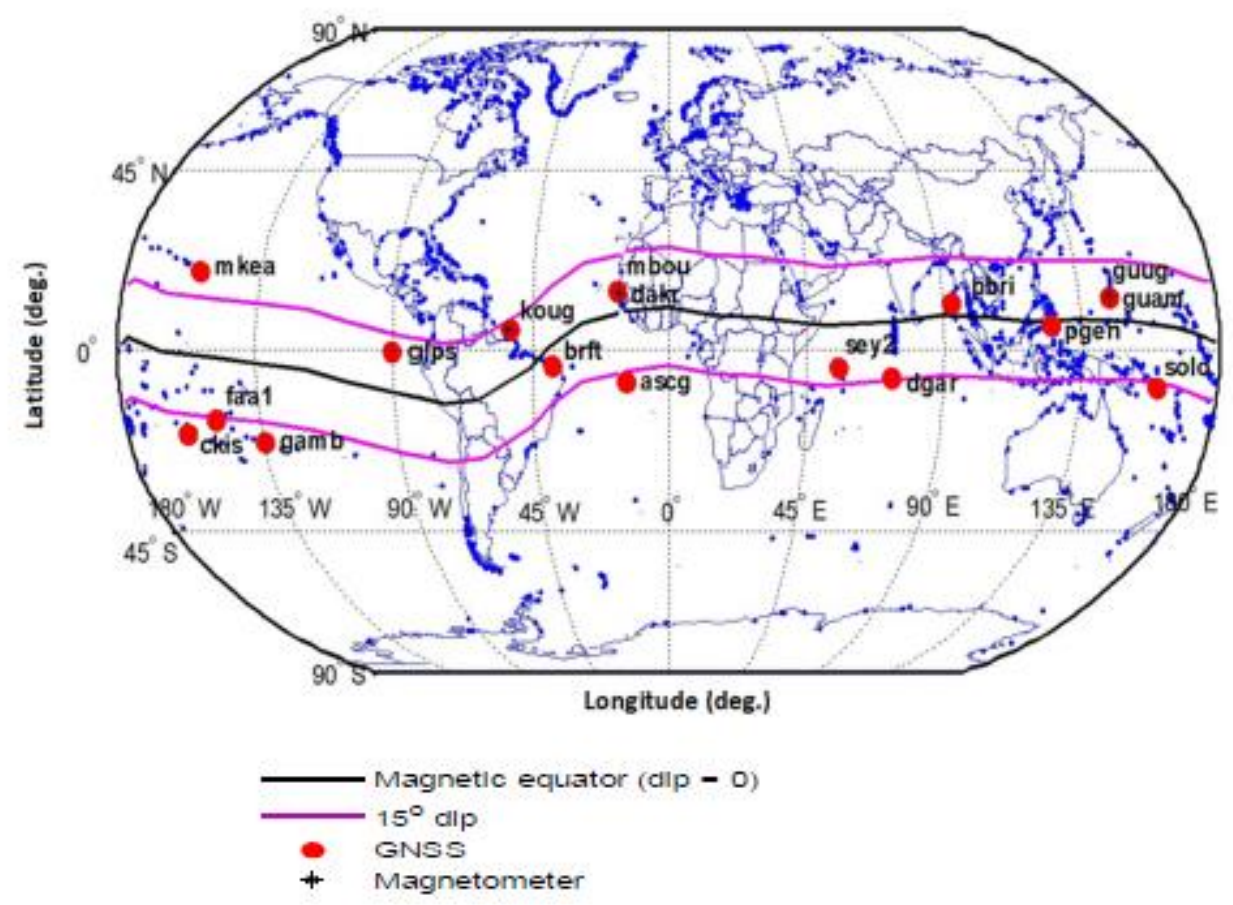

Figure 1: Geographic locations of the GNSS and magnetometer stations 


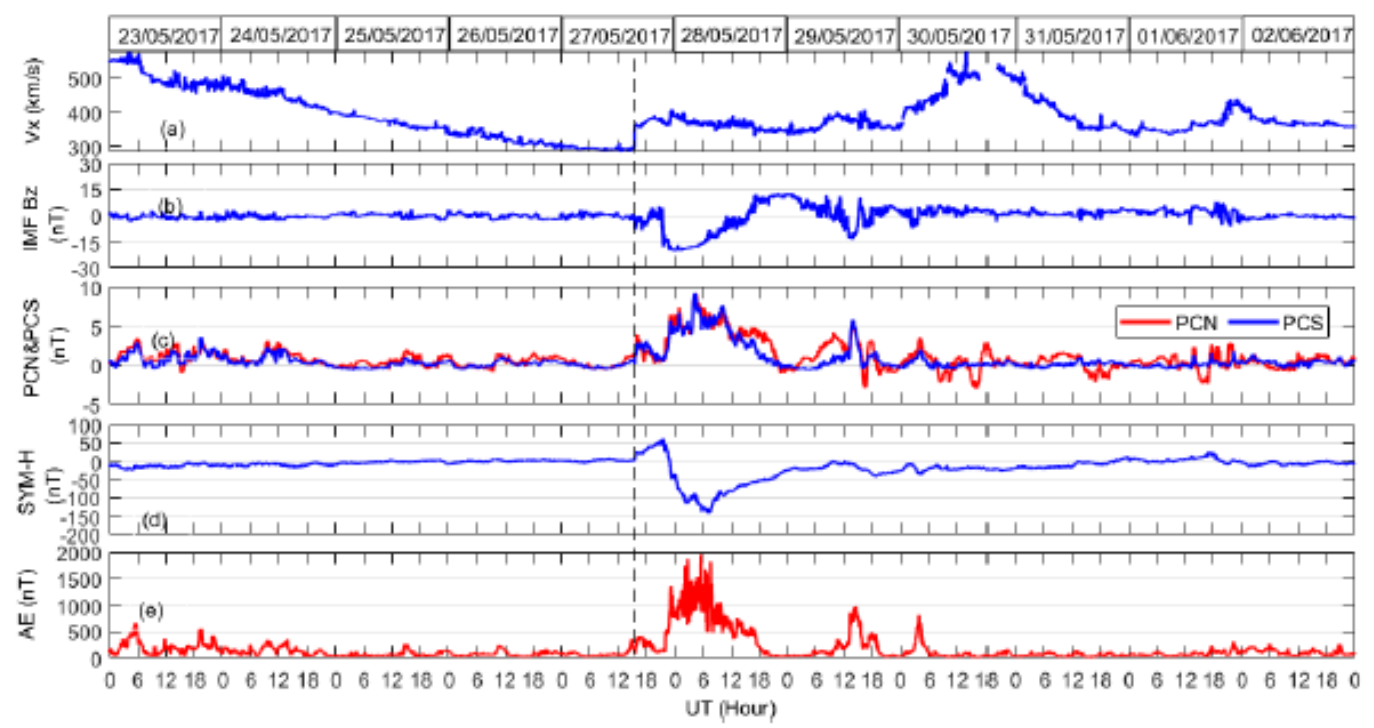

Figure 2: Variations of: (a) Solar Wind Plasma Speed, Vx (km/s), (b) IMF Bz (nT), (c) Polar Cap North (PCN) and Polar Cap South (PCS) indices (mV/m), (d) SYM-H (nT) and (e) Auroral Electrojet index (nT) from 23 May to 01 June 2017. The broken line represents the arrival of the shock on the Earth magnetosphere. 


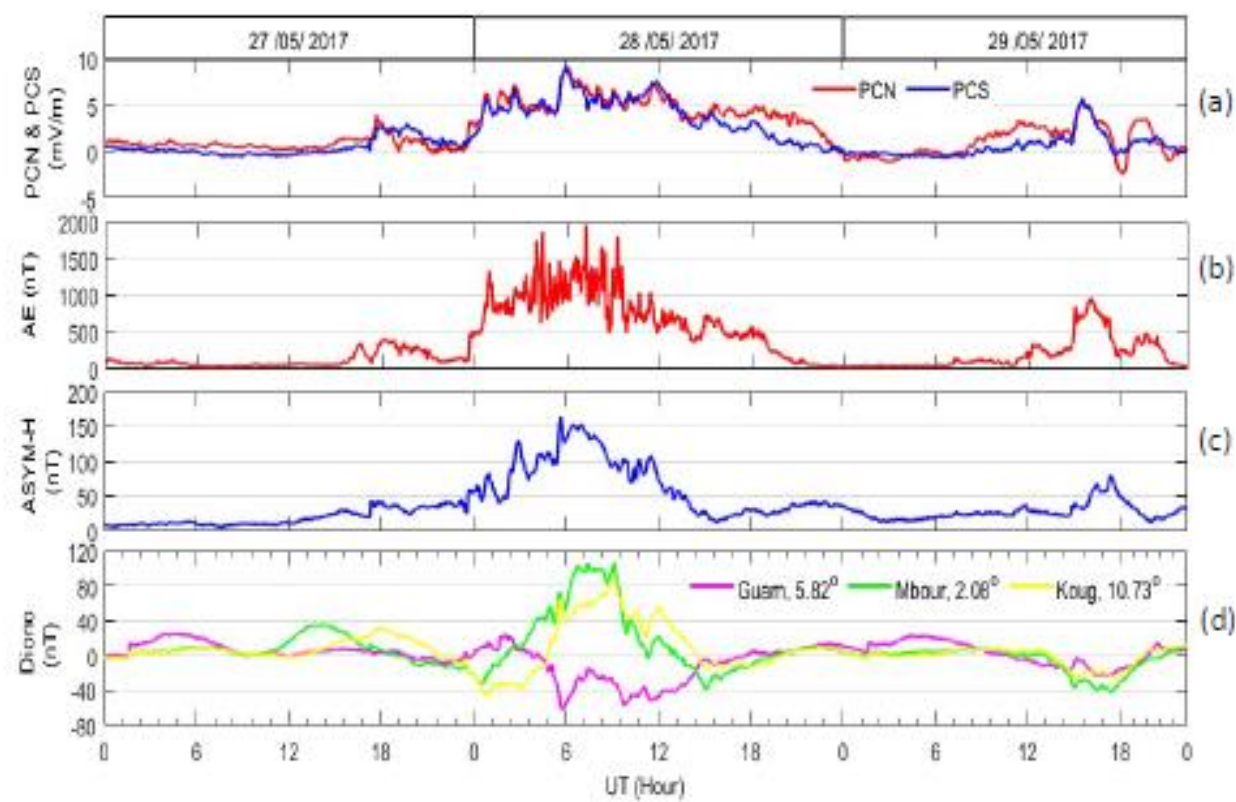

Figure 3: (a) Polar Cap North (PCN) and Polar Cap South (PCS) indices (mV/m), (b) Auroral Electrojet index (nT) (c)ASYM-H (nT) and (d) Diono (nT) at Guam, Mbour and Kuog on a zoomed scale (27-29th May, 2017). 
(a)

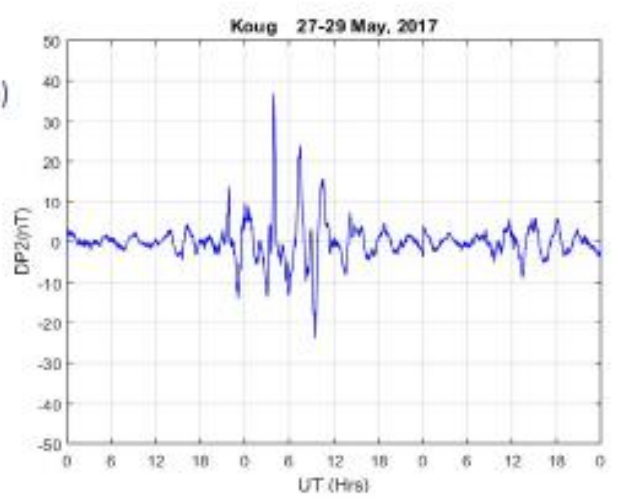

(b)

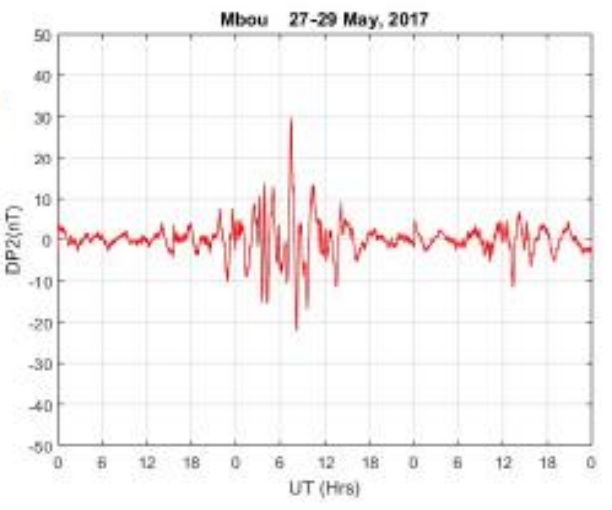

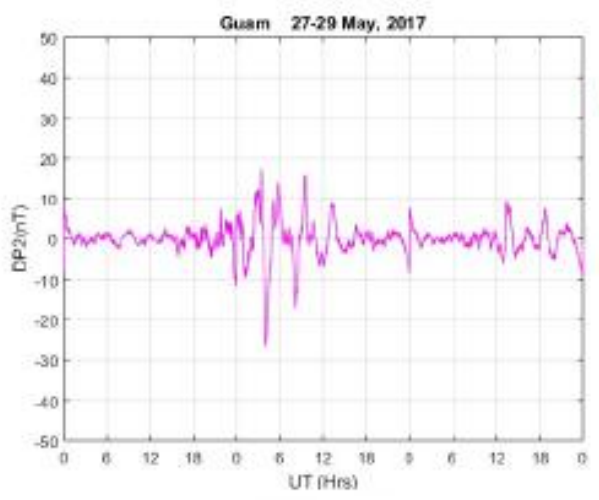

(c)

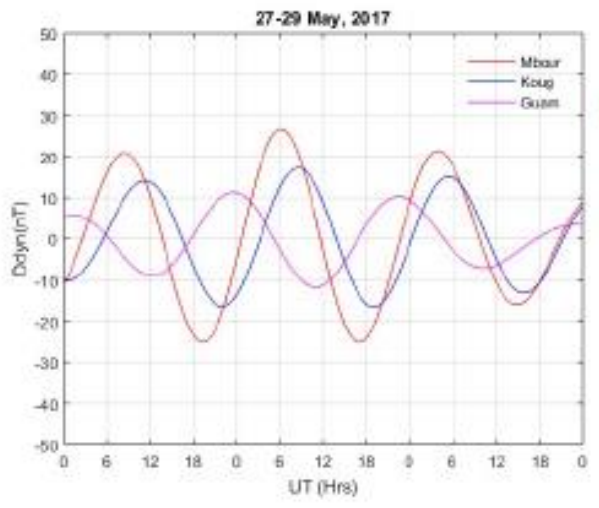

Figure 4: DP2 plots for 27-29th May, 2017 at: (a) Kourou,. (b) Mbour, (c) Guam and (d) Ddyn plots for the three magnetometer stations. 


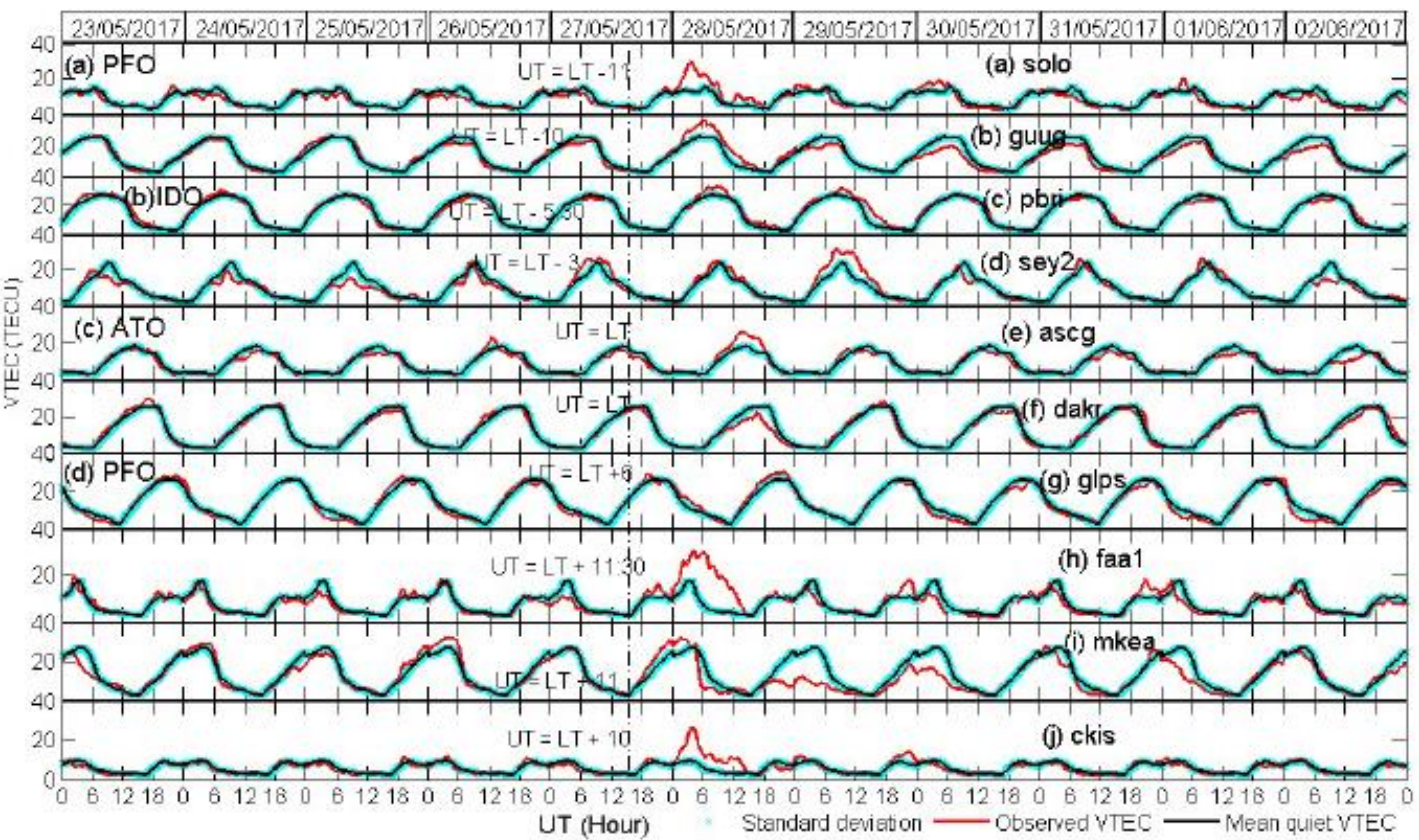

Figure 5: Variations of VTEC (red curve), monthly mean quiet TEC (back curve) and standard deviation used to represent the day-day variation of VTEC (cyan area) from 23rd May-2nd June, 2017 over: Pacific Ocean (PFO) Asian longitude: (a) Solomon Island [solo]; Indian Ocean (IDO): (b) Guam [guug], (c) Port Blair [pbri], (d) Republic of Seychelles [sey2]; Atlantic Ocean (ATO): (e) Ascension Island [ascg], (f) Dakar [dakr]; Pacific Ocean (PFO) American longitude: (g) Galapagos [glbs], (h) Tahiti [faa1], (i) Mauna Kea [mkea], (j) Cook Island [ckis] 


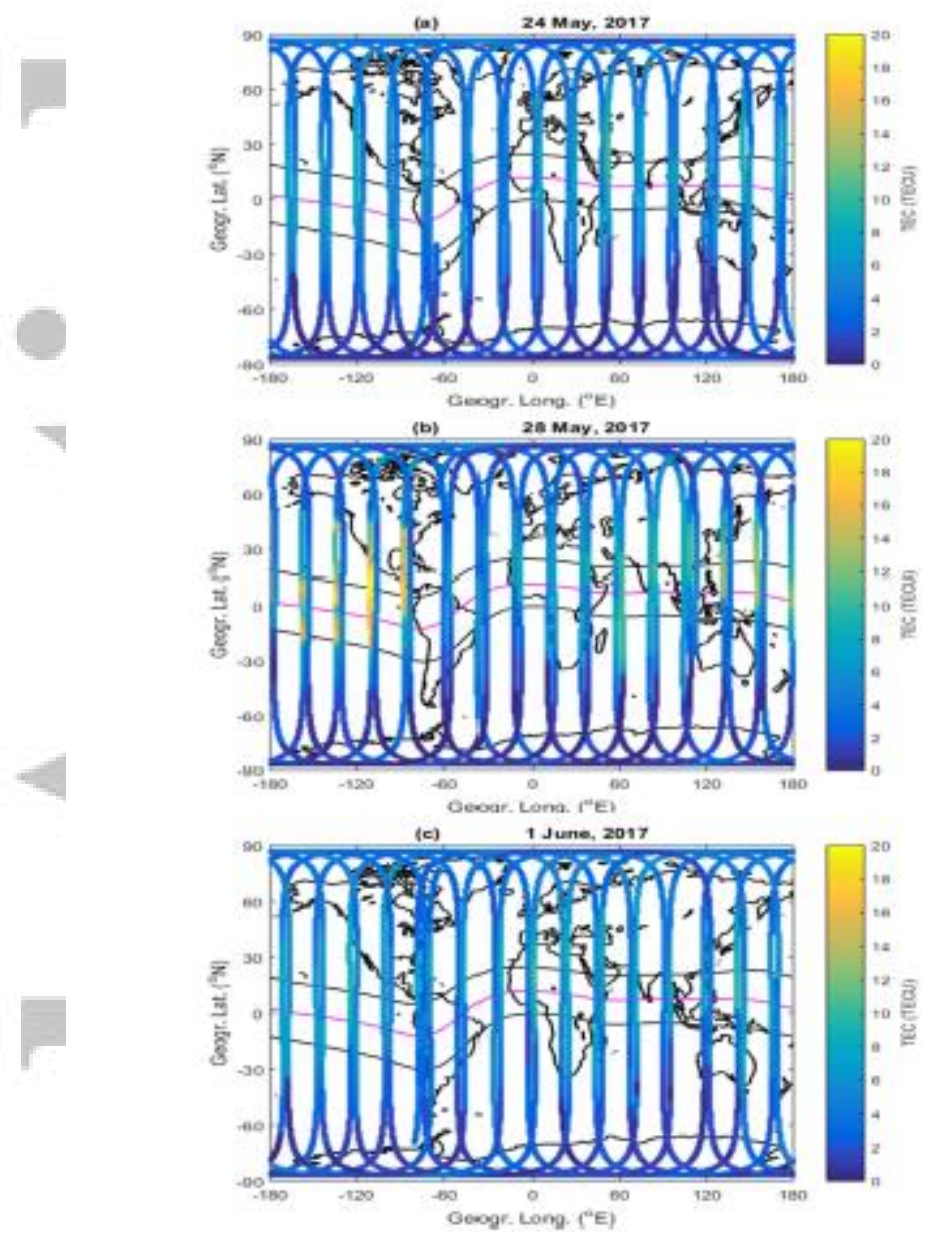

Figure 6: Global daily variations of SWARM A TEC on: (a) 24 May, 2017 (b) 28 May, 2017 and (c) 1 June, 2017. The magenta line on the map represents the magnetic equator, while the two black lines represent \pm 15 magnetic latitudes. 


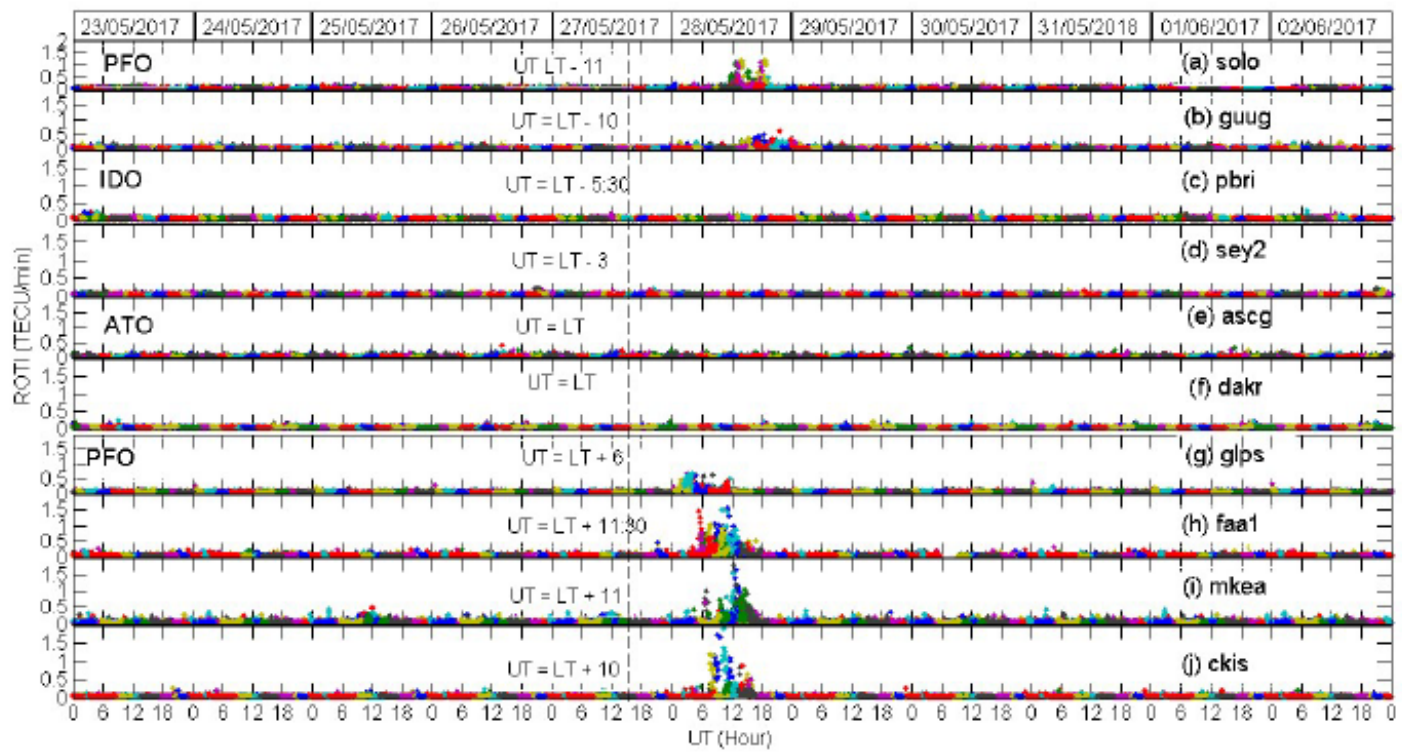

Figure 7: ROTI as proxy for ionospheric irregularities from 23rd May-1st June, 2017 over: Pacific Ocean (PFO) Asian longitude: (a) Solomon Island [solo]; Indian Ocean (IDO): (b) Guam [guug], (c) Port Blair [pbri], (d) Republic of Seychelles [sey2]; Atlantic Ocean (ATO): (e) Ascension Island [ascg], (f) Dakar [dakr]; Pacific Ocean (PFO) American longitude: (g) Galapagos [glbs], (h) Tahiti [faa1], (i) Mauna Kea [mkea], (j) Cook Island [ckis] 
(a)

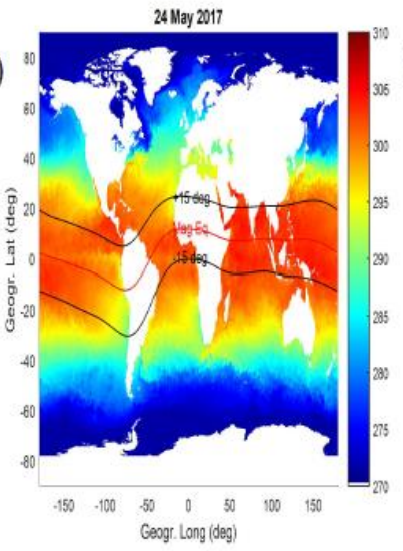

(b)

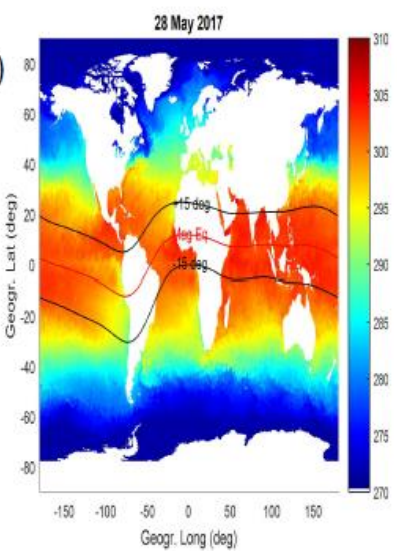

(c)

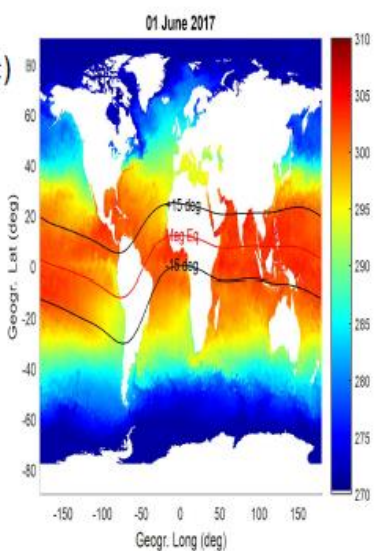

Figure 8: Sea Surface Temperature on (a) 24th May, 2017, (b) 28th May, 2017 and (c) 1st June, 2017

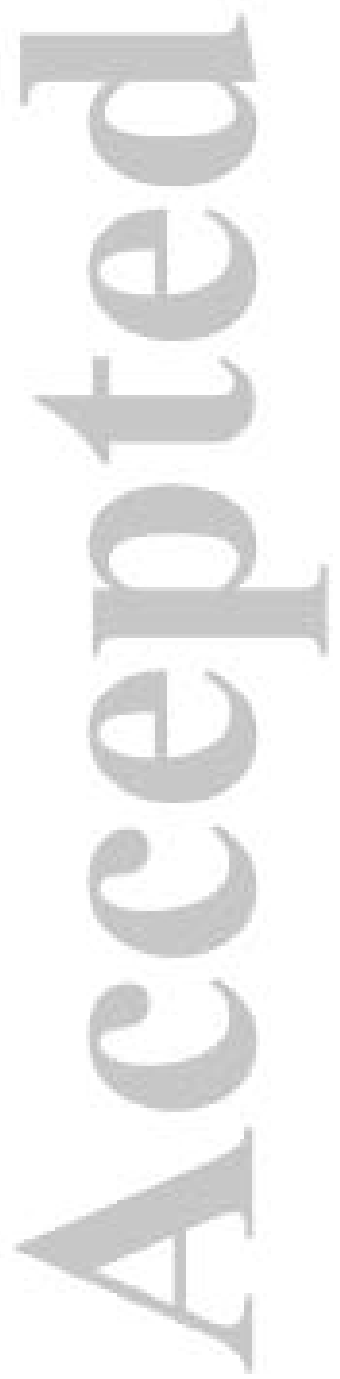




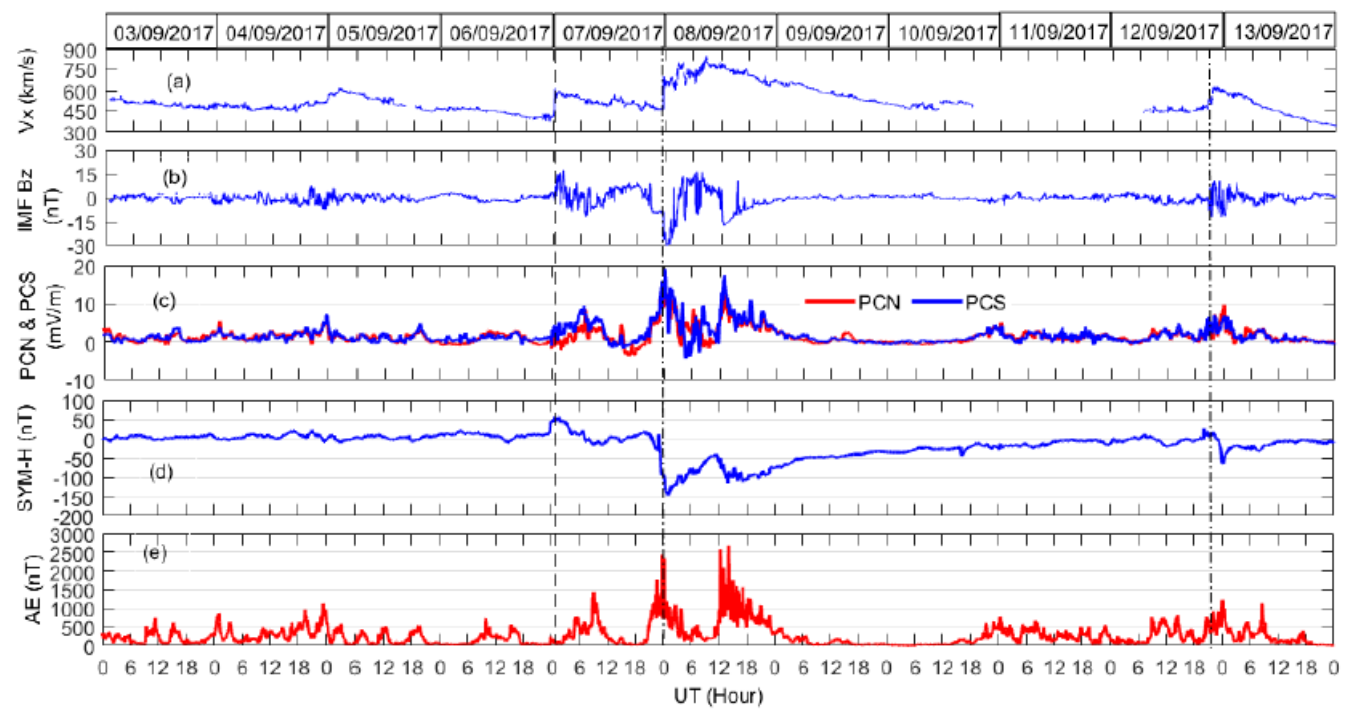

Figure 9: Variations of: (a) Solar Wind Plasma Speed, Vx (km/s), (b) IMF Bz (nT), (c) Polar Cap North (PCN) and Polar Cap South (PCS) indices (mV/m), (d) SYM-H (nT) and (e) Auroral Electrojet index (nT) from 313th September, 2017. The broken line represents the arrival of the shock on the Earth magnetosphere. 


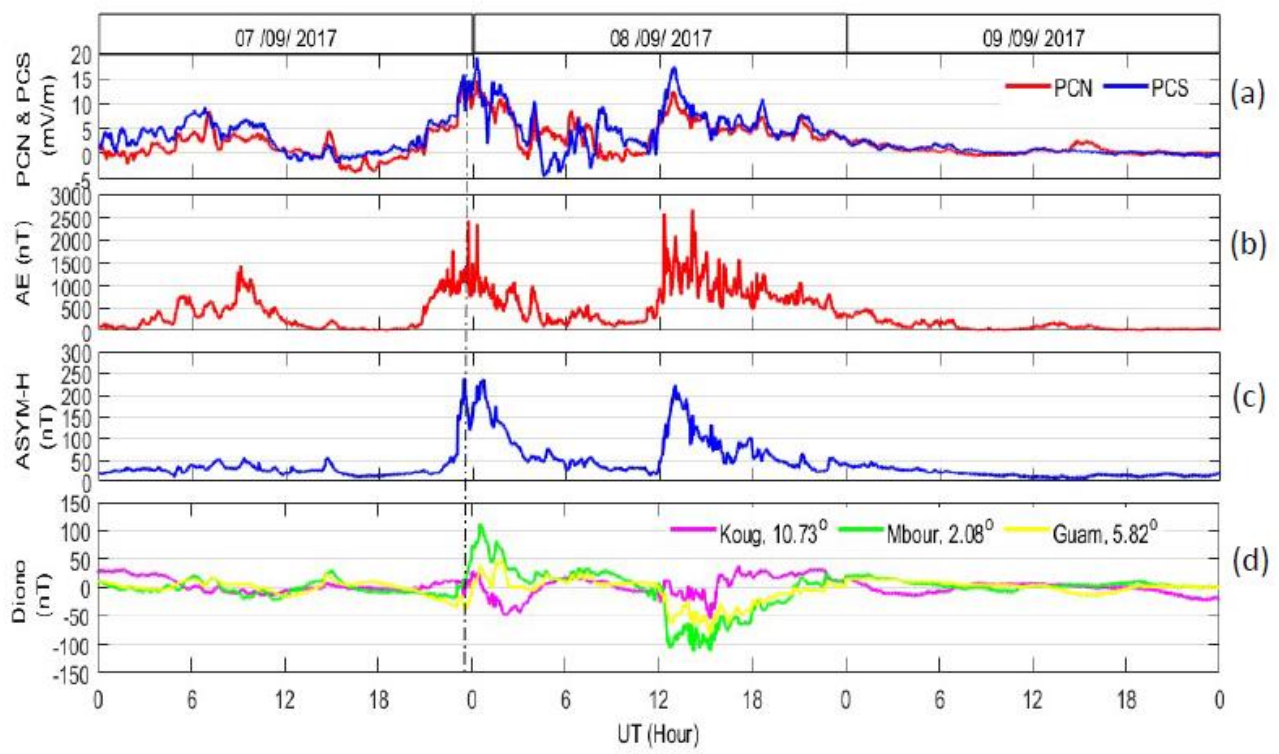

Figure 10: (a) Polar Cap North (PCN) and Polar Cap South (PCS) indices (mV/m), (b) Auroral Electrojet index (nT) (c) ASYM-H (nT) and (d) Diono (nT) at Guam, Mbour and Kuo on a zoomed scale (7-9th September, 2017). 
(a)

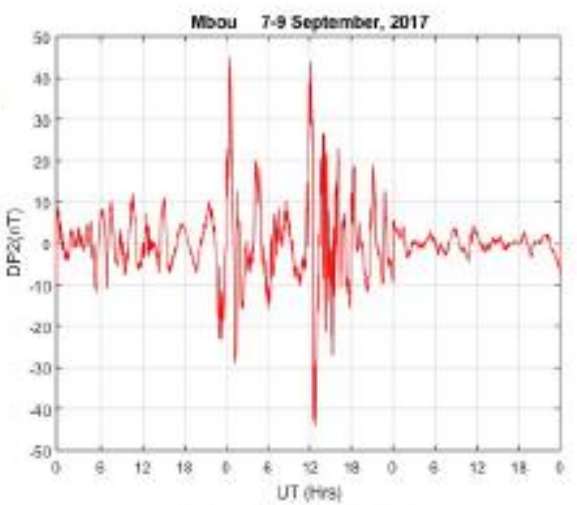

(b)

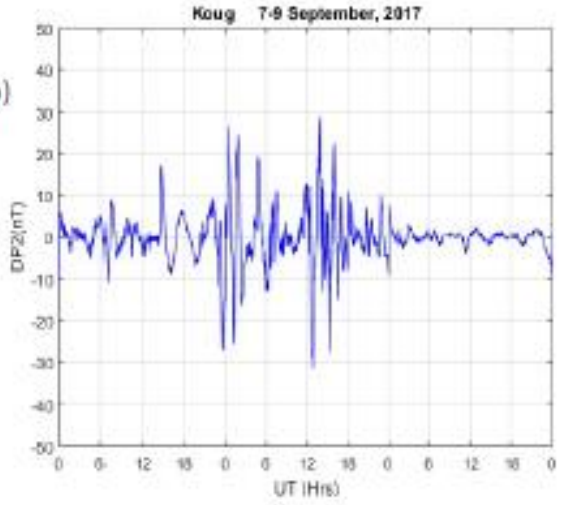

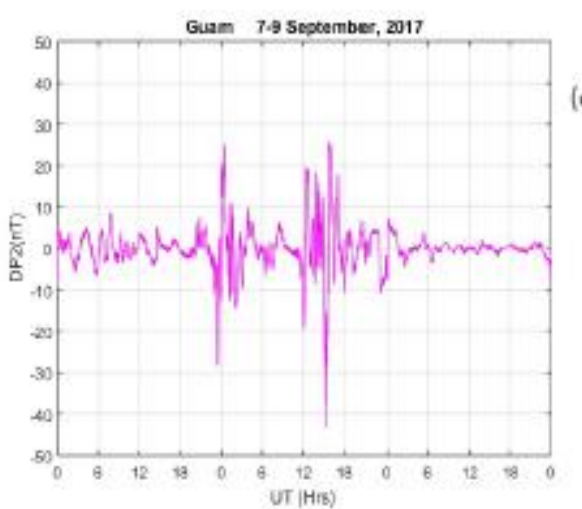

$7 \cdot 9$ Sephember, 2017

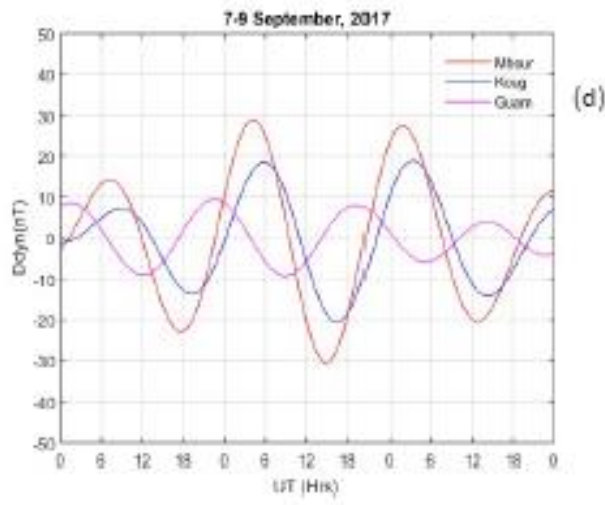

(c)

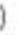

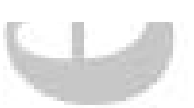

Figure 11: DP2 plots for 7-9th September, 2017 at: (a) Kourou,. (b) Mbour, (c) Guam and (d) Ddyn plots for the three magnetometer stations.

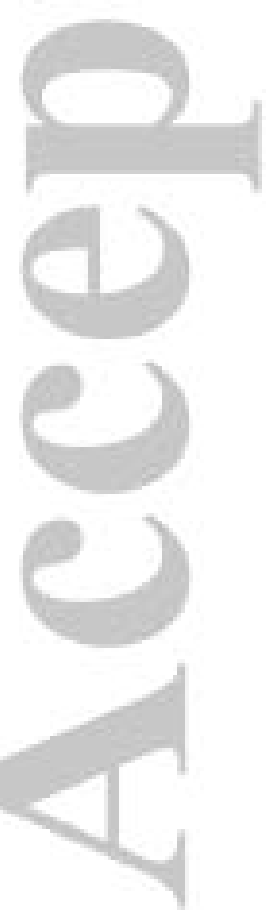




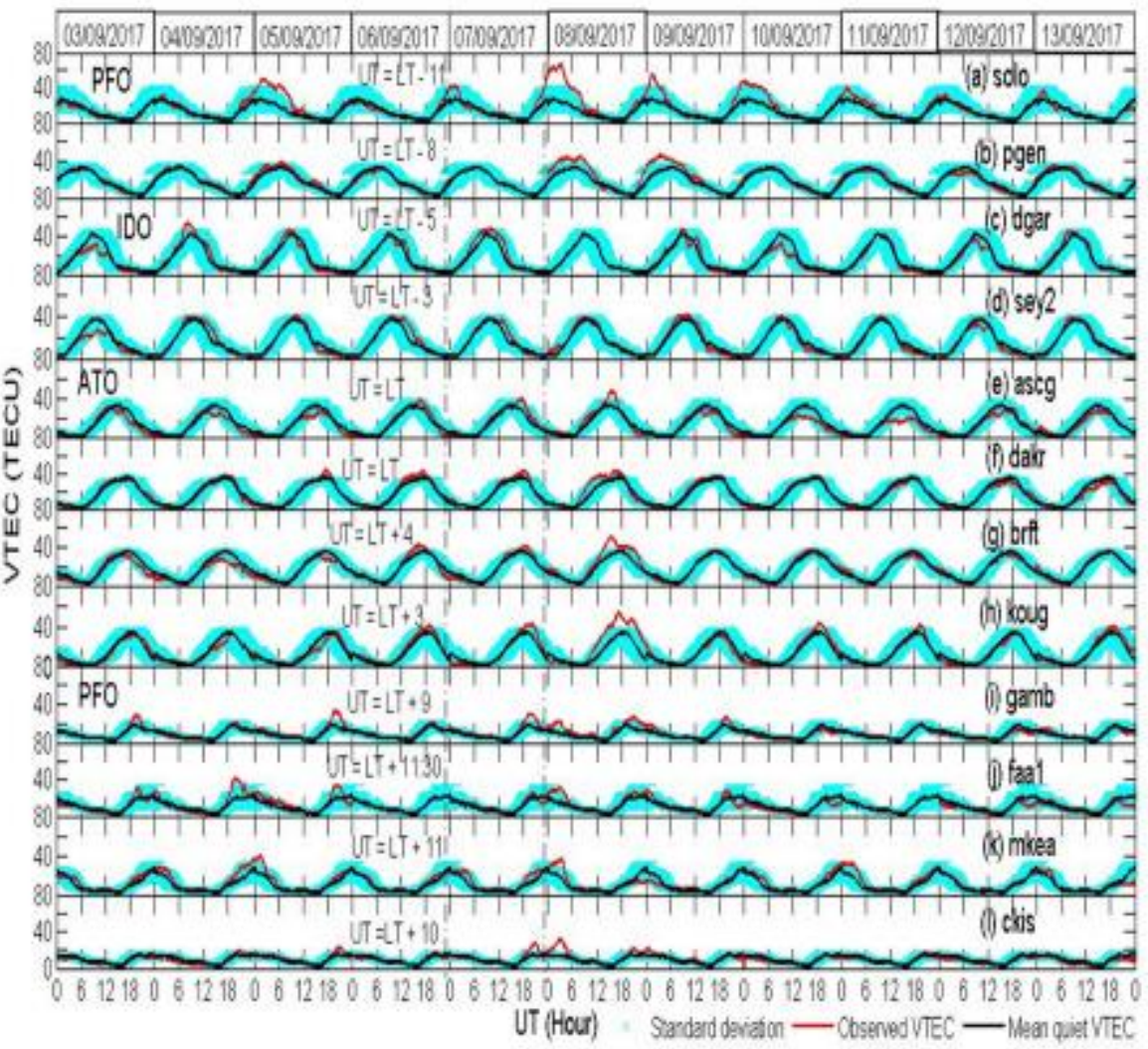

Figure 12: VTEC (red curve), monthly mean quiet TEC (back curve) and standard deviation use to represent the day-day variation in VTEC (cyan area) from 3rd-13th September, 2017 over: Pacific Ocean (PFO) Asian longitude:

(a) Solomon Island [solo]; (b) Namria General Santos [pgen], Indian Ocean (IDO): (c) Diego Garcia [dgar],

(d) Republic of Seychelles [sey2]; Atlantic Ocean (ATO): (e) Ascension Island [ascg], (f) Dakar [dakr], (g)Fortaleza [brft], (h) Kourou [koug]; Pacific Ocean (PFO) American longitude: (i) Risiketea [gamb], (j) Tahiti [faa1],

(k) Mauna Kea [mkea], (l) Cook Island [ckis] 


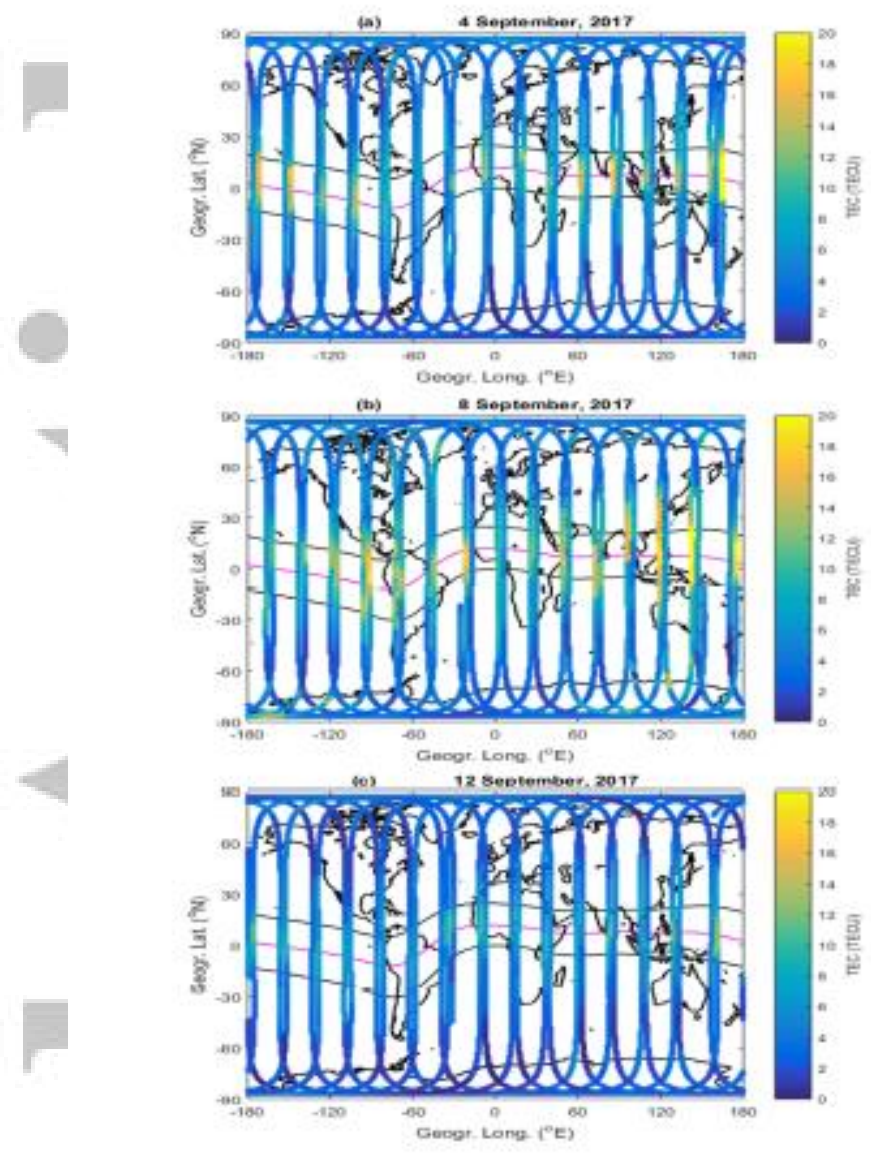

Figure 13: Global daily variations of SWARM A TEC on: (a) 4 September, 2017 (b) 8 September, 2017 and (c) 12 September, 2017. The magenta line on the map represents the magnetic equator, while the two black lines represent \pm 15 magnetic latitudes. 


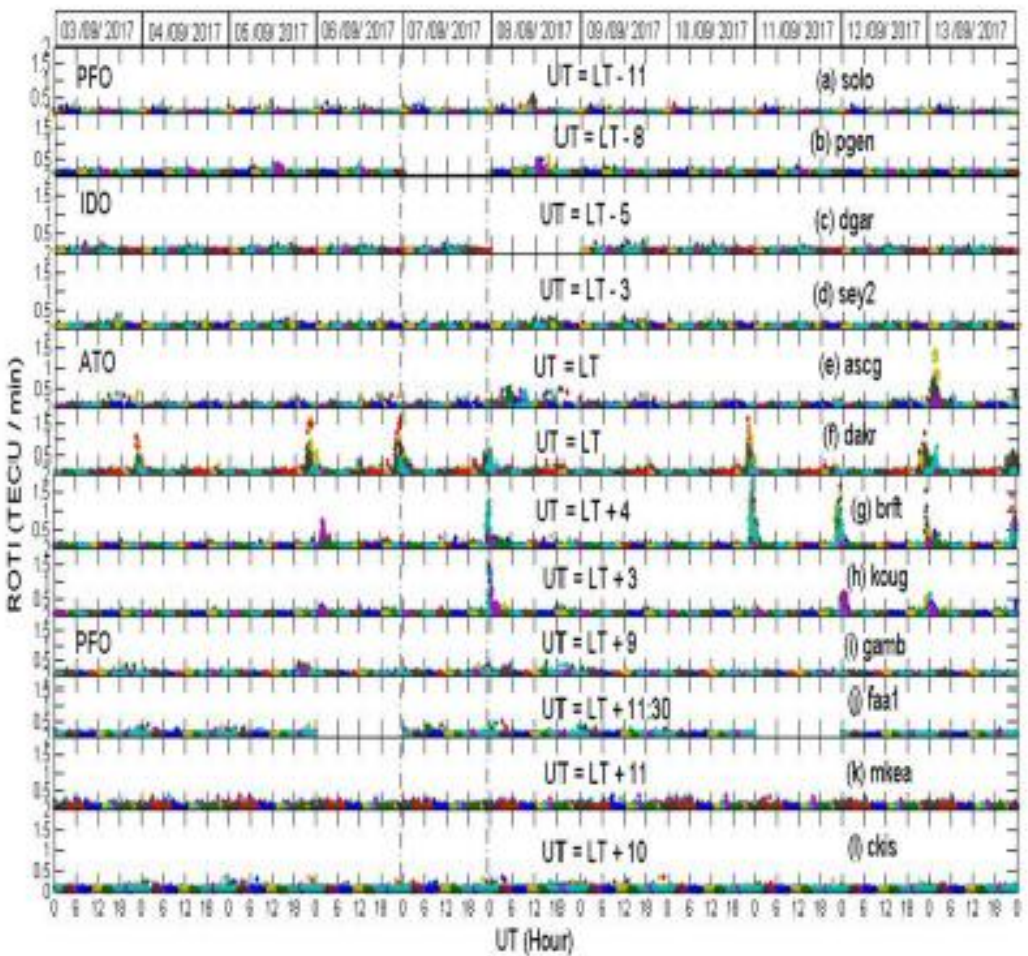

Figure 14: ROTI as proxy for ionospheric irregularities from 3rd-13th September, 2017over: Pacific Ocean (PFO) Asian longitude: (a) Solomon Island [solo]; (b) Namria General Santos [pgen], Indian Ocean (IDO):

(c) Diego Garcia [dgar], (d) Republic of Seychelles [sey2]; Atlantic Ocean (ATO): (e) Ascension Island [ascg], (f) Dakar [dakr], (g)Fortaleza [brft], (h) Kourou [koug]; Pacific Ocean (PFO) American longitude: (i) Risiketea [gamb], (j) Tahiti [faa1], (k) Mauna Kea [mkea], (l) Cook Island [ckis] 
(a)
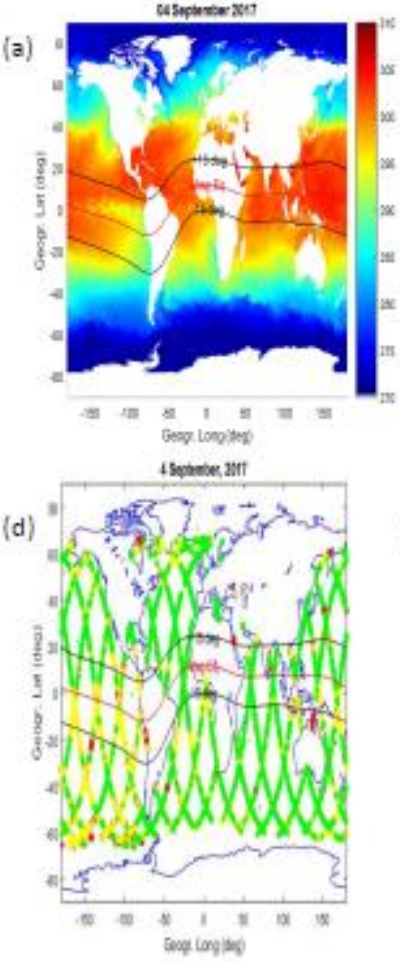

(b)

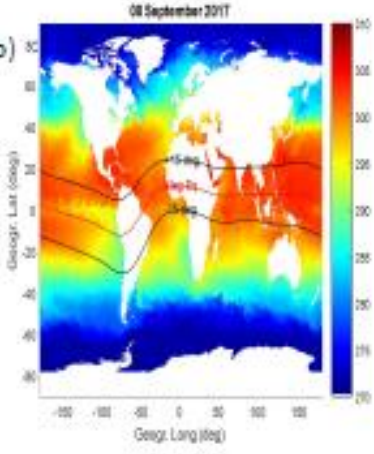

(e)

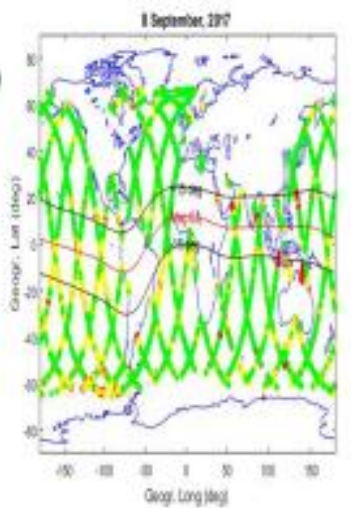

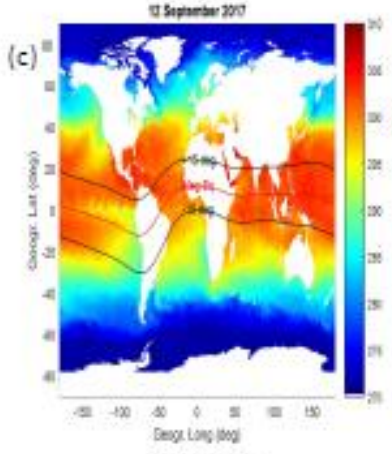

(f)

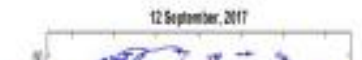

(f)

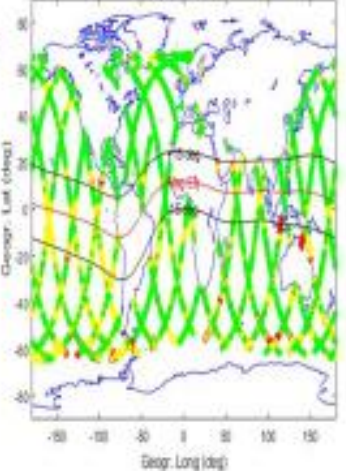

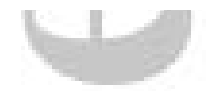

Figure 15: Sea Surface Temperature on (a) 24th May, 2017, (b) 28th May, 2017 and (c) 1st June, 2017, Sea Level Anomaly (d) 24th May, 2017, (e) 28th May, 2017 and (f) 1st June, 2017

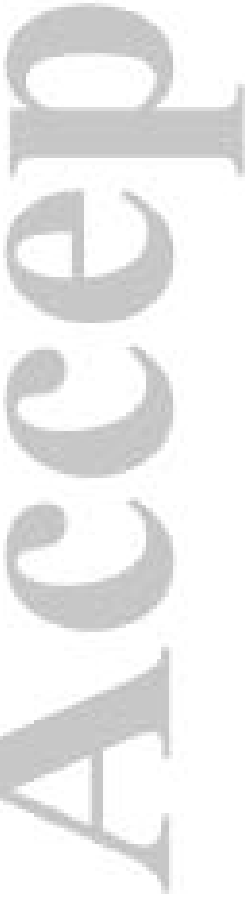

